\title{
Short-term variation in the isotopic composition of organic matter allocated from the leaves to the stem of Pinus sylvestris: effects of photosynthetic and postphotosynthetic carbon isotope fractionation
}

\author{
ELKE BRANDES*1, NAOMI KODAMA*1, KATHERINEWHITTAKER†, \\ CHRISTOPHER WESTON†, HEINZ RENNENBERG*, CLAUDIA KEITEL \\ MARK A. ADAMS§ and ARTHUR GESSLER †† \\ *Institute of Forest Botany and Tree Physiology, University of Freiburg, Georges-Köhler Allee 53/54, 79085 Freiburg, Germany, \\ $\dagger$ School of Forest and Ecosystem Science, University of Melbourne, Water Street, Creswick, VIC 3363, Australia, \\ $\ddagger$ Environmental Biology Group, Research School of Biological Sciences, Australian National University, Canberra, ACT, Australia, \\ §University of Western Australia, Ecosystem Research Group. Nedlands, WA, Australia
}

\begin{abstract}
We aimed to quantify the separate effects of photosynthetic and postphotosynthetic carbon isotope discrimination on $\delta^{13} \mathrm{C}$ of the fast-turn-over carbon pool (water soluble organic carbon and $\mathrm{CO}_{2}$ emitted from heterotrophic tissues), including their diel variation, along the pathway of carbon transport from the foliage to the base of the stem.

For that purpose, we determined $\delta^{13} \mathrm{C}$ in total and water-soluble organic matter of the foliage plus $\delta^{13} \mathrm{C}$ and $\delta^{18} \mathrm{O}$ in phloem organic matter of twigs and at three heights along the stem of Pinus sylvestris over a nine-day period, including four measurements per day. These data were related to meteorological and photosynthesis parameters and to the $\delta^{13} \mathrm{C}$ of stem-emitted $\mathrm{CO}_{2}$.

In the canopy (foliage and twigs), the $\delta^{13} \mathrm{C}$ of soluble organic matter varied diurnally with amplitudes of up to $1.9 \%$. The greatest ${ }^{13} \mathrm{C}$ enrichment was recorded during the night/early morning, indicating a strong influence of starch storage and remobilization on the carbon isotope signatures of sugars exported from the leaves. ${ }^{13} \mathrm{C}$ enrichment of soluble organic matter from the leaves to the twig phloem and further on to the phloem of the stem was supposed to be a result of carbon isotope fractionation associated with metabolic processes in the source and sink tissues. $\mathrm{CO}_{2}$ emitted from the stem was enriched by 2.3-5.2\% compared with phloem organic matter. When day-to-day variation was addressed, water-soluble leaf $\delta^{13} \mathrm{C}$ and twig phloem $\delta^{18} \mathrm{O}$ were strongly influenced by $c_{\mathrm{i}} / c_{\mathrm{a}}$ and stomatal conductance $\left(G_{\mathrm{s}}\right)$, respectively.

These results show that both photosynthetic and postphotosynthetic carbon isotope fractionation influence $\delta^{13} \mathrm{C}$ of organic matter over time, and over the length of the basipetal transport pathway. Clearly, these influences on the $\delta^{13} \mathrm{C}$ of respired $\mathrm{CO}_{2}$ must be considered when using the latter for partitioning of ecosystem $\mathrm{CO}_{2}$ fluxes or when the assessment of $\delta^{13} \mathrm{C}$ in organic matter is applied to estimate environmental effects in $c_{\mathrm{i}} / c_{\mathrm{a}}$. Keywords: carbon and oxygen isotopes, carbon transport, phloem, respiration, transitory starch
\end{abstract}

Received 11 October 2005; revised version received 23 March 2006; accepted 10 April 2006

Correspondence: Arthur Gessler, tel. + 49175 1505030, e-mail: arthur.gessler@sonne.uni-freiburg.de

${ }^{1}$ These authors contributed equally to this paper.
Introduction

While isotope discrimination processes during photosynthetic $\mathrm{CO}_{2}$ fixation are well described, there is a lack of information on fractionation steps of following metabolic pathways and transport processes, that are collectively referred to as postphotosynthetic fractionation 
(Badeck et al., 2005). Fractionations due to equilibrium and kinetic isotope effects result in differences in isotopic signatures among metabolites and intramolecular positions (Schmidt, 2003; Tcherkez \& Farquhar, 2005). Postphotosynthetic carbon isotope fractionation, thus, leads to differences in the $\delta^{13} \mathrm{C}$ signature of organic matter in different plant organs and chemical fractions, especially if there are different isotopic compositions of exported and nonexported compounds (Helle \& Schleser, 2004; Hobbie \& Werner, 2004). It may be also responsible for diel variation in $\delta^{13} \mathrm{C}$ of sugars exported from leaves (Tcherkez et al., 2004) because transitory starch - the major origin of sucrose loaded into the phloem during night - is known to carry a $\delta^{13} \mathrm{C}$ signature that can be up to about $4 \%$ greater than triose-P originating directly from the pentose phosphate cycle (Gleixner et al., 1998).

In addition, nonrandom distribution of ${ }^{13} \mathrm{C}$ in hexose phosphate substrates and fragmentation fractionation during respiration can be responsible for an enrichment of $\mathrm{CO}_{2}$ released from respiration (Tcherkez et al., 2003, 2004; Nogues et al., 2004) that can vary depending on time (Damesin \& Lelarge, 2003; Hymus et al., 2005) and plant organ (Badeck et al., 2005).

These intraplant gradients and diel variations in $\delta^{13} \mathrm{C}$ of organic matter, as well as potential differences in isotope fractionation during respiration at different positions within plants, may be relevant to: (a) approaches that use the isotopic signature of $\mathrm{CO}_{2}$ exchange fluxes at the ecosystem level for the elucidation of $\mathrm{CO}_{2}$ sinks and sources (Pataki et al., 2003; Badeck et al., 2005), and, (b) the interpretation of $\delta^{13} \mathrm{C}$ in different plant tissues as a time-integrating proxy for environmental effects on $c_{\mathrm{i}} / c_{\mathrm{a}}$ (Keitel et al., 2003; Helle \& Schleser, 2004).

The assessment of the variations in $\delta^{13} \mathrm{C}$ of newly fixed carbon from leaves and the comparison with the carbon isotopic signatures of leaf exported sugars in the phloem along the axis of trees is a useful tool in assessing both photosynthetic and postphotosynthetic carbon isotope discrimination. Gessler et al. (2004) showed that variations in $g_{\mathrm{s}}$ and, thus, $c_{\mathrm{i}} / c_{\mathrm{a}}$ could explain ca. $70 \%$ of the variation in $\delta^{13} \mathrm{C}$ of phloem allocated carbon in beech with an assumption that additional postphotosynthetic fractionation was responsible for further differences in carbon isotope signature among leaf carbon components and between leaf carbon and transported carbon.

For adult trees and under field conditions, spatial and temporal variation pose major problems in differentiating postphotosynthetic carbon isotope fractionation associated with carbon allocation, from photosynthetic discrimination. A common assumption is that sugars extracted from the phloem of stems or roots have had a longer residence time within the plant than sugars extracted from the leaves or from the twig phloem. Depending on environmental conditions and/or transport velocities, there is the possibility that locally independent carbon pools at different positions along a tree axis may carry $\delta^{13} \mathrm{C}$ signatures reflecting: (1) different $c_{\mathrm{i}} / c_{\mathrm{a}}$ values to the more recently produced carbon in leaves and (2) differences in storage and remobilization of transitory starch.

To start exploring these constraints to the use of $\delta^{13} \mathrm{C}$ signatures of $\mathrm{CO}_{2}$, plant tissues and metabolites, we determined the carbon isotope composition of water soluble organic matter and respired $\mathrm{CO}_{2}$ of Scots pine (Pinus sylvestris) with moderately high resolution in space and time. Over 9 consecutive days, we assessed the carbon isotope composition of total and water-soluble organic matter in needles (previous and current year) and of organic matter in the phloem (four positions from the twigs to the stem base), four times each day. In addition, we analysed $\delta^{13} \mathrm{C}$ values of $\mathrm{CO}_{2}$ effluxed from stems (two positions) on a daily basis and assessed $\delta^{18} \mathrm{O}$ in phloem organic matter. The $\delta^{18} \mathrm{O}$ signature shares dependence on stomatal conductance with $\delta^{13} \mathrm{C}$ signature but is not dependent on RubisCo activity (Barbour et al., 2000a, 2001). Cernusak et al. (2005) also showed that $\delta^{18} \mathrm{O}$ of phloem sugars in Eucalyptus globulus was closely related to photosynthesis-weighted leaf water ${ }^{18} \mathrm{O}$ enrichment, suggesting little postphotosynthetic variation. Hence, in addition to combined analysis of $\delta^{18} \mathrm{O}$ and $\delta^{13} \mathrm{C}$ helping separate the effects of stomatal conductance and carbon fixation on photosynthetic carbon isotope discrimination (Scheidegger et al., 2000; Adams \& Grierson, 2001; Cernusak et al., 2004), it may also help differentiate photosynthetic and postphotosynthetic alteration of carbon isotope composition.

We aimed to test the following working hypotheses:

(1) Changes of $c_{\mathrm{i}} / c_{\mathrm{a}}$ that are imprinted in the carbon isotope signature of newly fixed organic matter can be traced - with particular time lags - from the leaves to the phloem along the tree axis and influence $\delta^{13} \mathrm{C}_{\text {of }} \mathrm{CO}_{2}$ emitted from heterotrophic tissues. Tracking this $\delta^{13} \mathrm{C}$ signal along the plant axis with time allows the estimation of the time-dependent distribution of carbon within the plant.

(2) Postphotosynthetic fractionation steps alter $\delta^{13} \mathrm{C}$ of fast-turnover carbon pools and thus the isotopic composition of organic matter transported from the leaves to the stem.

\section{Materials and methods}

\section{Site description and plant material}

The experiments were conducted in a 38-year-old pine plantation in the valley of the southern upper Rhine 
near the village of Hartheim, Germany. The site is part of a long-term study by the Meteorological Institute of the University of Freiburg ( $201 \mathrm{~m}$ asl; $47^{\circ} 56^{\prime} \mathrm{N}$ and $7^{\circ} 37^{\prime} \mathrm{E}$ ) and is equipped with a $30 \mathrm{~m}$ high meteorological tower. The forest consists of Scots pine (P. sylvestris L.) with interspersed patches of P. nigra. All experiments were performed in plots of $P$. sylvestris. The mean height of trees ranged between 14 and $15 \mathrm{~m}$, and leaf area index (LAI) was $1.47 \mathrm{~m}^{2} \mathrm{~m}^{-2}$ owing to recent thinning. Stand density was 800 trees ha $^{-1}$ and aboveground biomass about $7.9 \mathrm{~kg} \mathrm{~m}^{2}$. The dominant plant species of the understorey were the grass Brachypodium pinnatum, the sedges Carex alba and Carex flacca, and the moss Scleropodium purum. The mean annual total precipitation as measured at the weather station Bremgarten of the DWD (Deutscher Wetterdienst) nearby was $667 \mathrm{~mm}$, and amounted to $413 \mathrm{~mm}$ during the growing season. Mean annual air temperature is $9.8^{\circ} \mathrm{C}$ and mean air temperature during the growing season is $15.4^{\circ} \mathrm{C}$. The forest grows on a Calcaric Regosol, the soil textural class is sandy silt. The $\mathrm{pH}$ value of the upper soil layer lies between 7.6 and 8.3. For a detailed site description, see Mayer et al. (2000).

We selected four representative dominant or codominant individuals of $P$. sylvestris ca. $1000 \mathrm{~m}$ distance from the meteorological measurement tower. The canopy of the trees and the upper parts of the stems were accessed using a $25 \mathrm{~m}$ hydraulic lift installed on a truck. The measurement campaign began on 1 July 2004 and was completed on 9 July 2004. Plant samples were collected four times each day: in the morning (between 8:00 and 10:00 hours), at midday/afternoon (12:45-15:00 hours), in the evening (17:30-20:00 hours) and during night (22:00-01:00 hours). At each sampling time, current and previous year needles from the sunlit part of the upper canopy were harvested separately and immediately frozen in liquid nitrogen. In addition, small bark pieces (ca. $150 \mathrm{mg}$ FW) from the same twig where the needles were collected were sampled using scalpels. Trunk bark pieces (diameter $13 \mathrm{~mm}$ ) were collected at ca. $10 \mathrm{~m}$ (stem-top), $6.0 \mathrm{~m}$ (stem-middle) and $1.5 \mathrm{~m}$ (stem-base). Both twig and trunk bark samples were used in phloem exudation studies.

\section{Meteorological parameters}

Meteorological data (air temperature, relative humidity, photosynthetic active radiation, precipitation) were determined continuously at the measurement tower by the Meteorological Institute of the University of Freiburg, Germany. Air temperature and humidity were measured using a psychrometer according to Frankenberger (Mayer \& Gietl, 1976) at $15.5 \mathrm{~m}$ height. PAR was determined by Li-190SZ-Sensors (Licor Inc., Lincoln,
NE, USA) at $29 \mathrm{~m}$, precipitation was measured at $30 \mathrm{~m}$. All meteorological data were calculated as halfhourly mean values.

\section{Transpiration, canopy stomatal conductance}

Prevailing conditions of water availability and climate were analysed by measuring xylem (water) flow densities using Granier-style probes and by scaling up flow densities from a single tree to the stand level (e.g. Granier et al., 1996; Kostner et al., 1998). Flow densities in the water-conducting sapwood of $P$. sylvestris were determined using the constant-heating method according to Granier (1985) and Kostner et al. (1996). Flux densities (FD: $\mathrm{mL} \mathrm{cm}^{-2}$ sapwood area s${ }^{-1}$ ) were determined every $5 \mathrm{~min}$ in 12 trees and calculated as means every $30 \mathrm{~min}$. Stand transpiration was estimated as the product of flux densities and stand sapwood area (SA; $\mathrm{m}^{2} \mathrm{~m}^{-2}$ ), accounting for a decrease in sap flow density

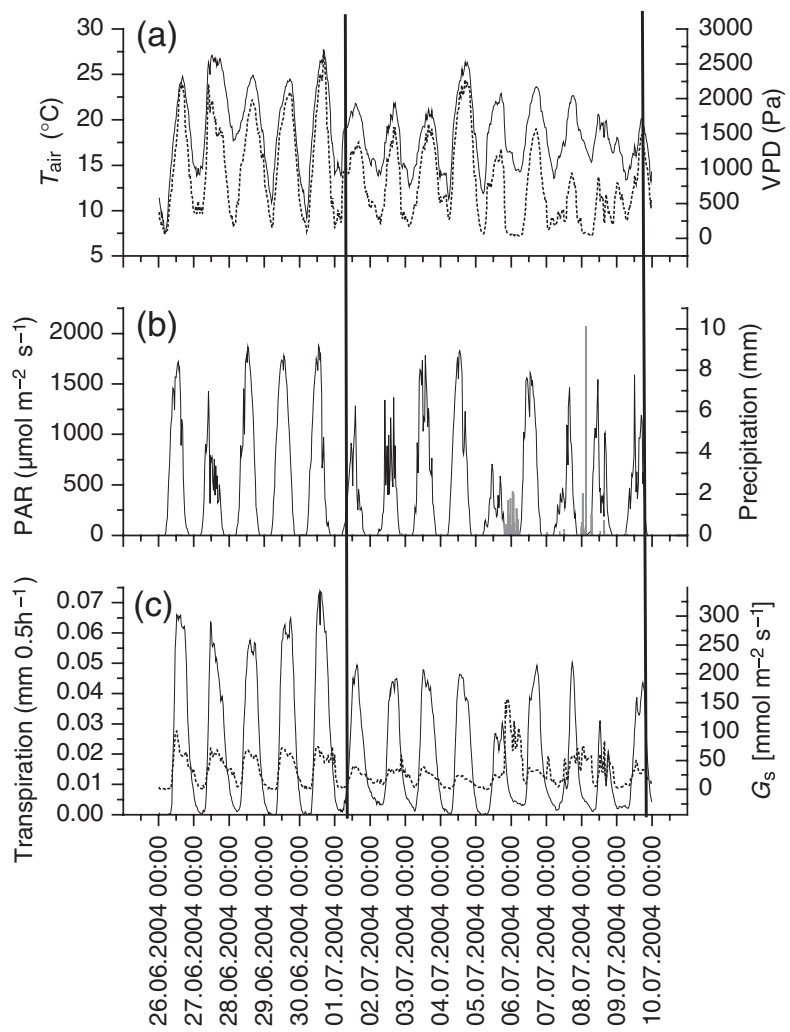

Fig. 1 Canopy air temperature ( $T_{\text {air, }}$ solid line) and water pressure deficit (VPD, dotted line) (a), photosynthetic active radiation (PAR, solid line) and precipitation (grey bars) above the canopy (b) and stand transpiration (solid line) and canopy stomatal conductance $\left(G_{\mathrm{s}}\right.$, dotted line) at the field site Hartheim between 26 June 2004 and 10 July 2004. The two bold vertical lines indicate start and end of the sampling of plant material (measurement campaign). 
within the sap wood with increasing distance from the cambium according to Kostner et al. (1996).

As stomatal conductance is one of the factors determining $\delta^{13} \mathrm{C}$ of organic carbon, canopy stomatal conductance $\left(G_{\mathrm{s}}, \mathrm{mmol} \mathrm{m}^{-2} \mathrm{~s}^{-1}\right.$; Fig. 2) was calculated using a simplified Penman-Monteith equation (according to Pataki et al., 1998 and Keitel et al., 2003):

$$
G_{\mathrm{s}}=\frac{G_{\mathrm{c}}}{L A I}=\frac{\gamma \lambda P}{\rho c_{\mathrm{p}} V P D R T} \frac{J_{s} S A}{L A I} 10^{3}
$$

where $G_{c}$ is the canopy conductance, $\gamma$ is the psychrometric constant $\left(\mathrm{kPa} \mathrm{K}^{-1}\right), \lambda$ is the latent heat of vaporization $\left(\mathrm{J} \mathrm{kg}^{-1}\right), \rho$ is the density of moist air $\left(\mathrm{kg} \mathrm{m}^{-3}\right)$, $c_{\mathrm{p}}$ is the heat capacity of moist air $\left(\mathrm{J} \mathrm{kg}^{-1} \mathrm{~K}^{-1}\right)$, VPD is the water vapour pressure deficit $(\mathrm{kPa}), P$ is the
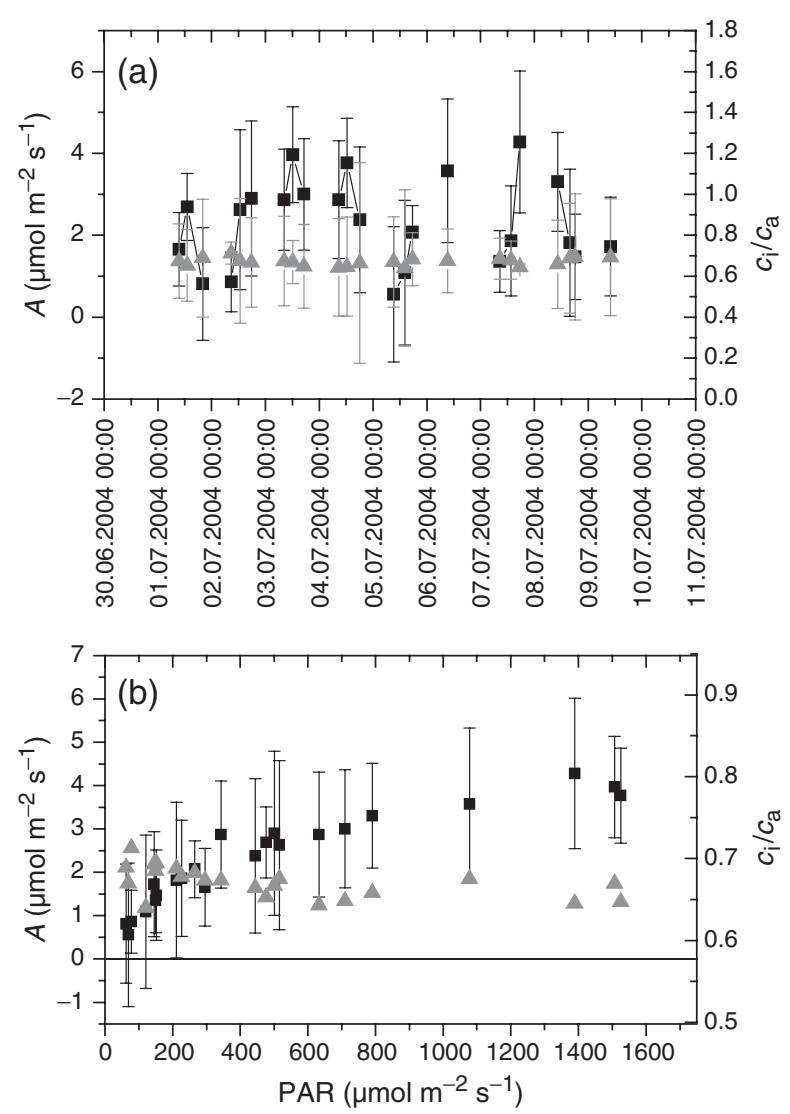

Fig. 2 Net assimilation $A$ (black squares) and $c_{\mathrm{i}} / c_{\mathrm{a}}$ (grey triangles) during the 9 days of measurement campaign (a) and as depending on ambient PAR during measurement (b). Data shown are mean values $( \pm S D)$ of measurements of four trees. Per tree three twigs with current and previous year's needles were measured at ambient temperature and light conditions. PAR was determined with the PAR-sensor installed in the leaf chamber holder of the portable photosynthesis measuring system and, thus, is representative for the actual radiation during the measurement. atmospheric pressure $(\mathrm{Pa}), R$ is the ideal gas constant $\left(8.31 \mathrm{~J} \mathrm{~mol}^{-1} \mathrm{~K}^{-1}\right), T$ is air temperature $(K), J_{\mathrm{s}}$ is mean daily sap flux density $\left(\mathrm{kg} \mathrm{m}^{-2} \mathrm{~s}^{-1}\right)$ and LAI is the leaf area $\left(\mathrm{m}^{2} \mathrm{~m}^{-2}\right)$. This calculation assumes that (1) sap flux densities are uniform throughout the cross-sectional sapwood area, (2) stem capacitance can be neglected, and (3) that canopy aerodynamic conductance is larger than $G_{\mathrm{s}}$ as reported by Whitehead \& Jarvis (1981) (i.e. aerodynamic resistance can be neglected compared with stomatal resistance).

Measurement of foliar net $\mathrm{CO}_{2}$-assimilation and $\mathrm{c}_{i} / \mathrm{c}_{a}$ and calculation of carbon isotope discrimination during photosynthesis

Net $\mathrm{CO}_{2}$ exchange was determined at the leaf level in the upper half of the canopy using a portable photosynthesis measuring system (LC A4; ADC, Hoddesdon, UK) three times during the light period of each day (morning: between 8:00 and 10:00 hours; midday: 12:4515:00 hours; evening: 17:30-20:00 hours).

From each of the four trees examined, three small twigs with needles attached (approximately $50 \%$ of the needle consisting of current, the other half of previous year's needles) were introduced into the needle leaf chamber of the LC A4 at each time point. Measurements of net $\mathrm{CO}_{2}$ assimilation and $c_{\mathrm{i}} / c_{\mathrm{a}}$ were conducted at ambient temperature and PAR level. In addition, stomatal conductance was determined in order to compare leaf level values with canopy stomatal conductance $\left(G_{\mathrm{s}}\right)$. All calculations were performed according to von Caemmerer \& Farquhar (1981). Leaf temperature was determined using a thermocouple. Projected area of the needles was determined with a leaf area meter $(\Delta \mathrm{T}$ Devices, Cambridge, UK). Mean length was determined from a sub-sample of needles. Three dimensional leaf area which was used as a basis for the net $\mathrm{CO}_{2}$ exchange values ( $\mu \mathrm{mol} \mathrm{CO} \mathrm{m}^{-2}$ 3-D leaf area) was then calculated assuming the needle to have the shape of a half-cylinder (Luoma, 1997; Haberer, 2002).

Carbon isotope discrimination $\left(\Delta^{13} \mathrm{C}\right)$ during photosynthesis is due to diffusional and enzymatic fractionation processes often described with a two stage model (diffusion through the stomata followed by carboxylation) according to Farquhar et al. (1982):

$$
\Delta^{13} \mathrm{C}=\mathrm{a}+(\mathrm{b}-\mathrm{a}) \frac{\mathrm{c}_{\mathrm{i}}}{\mathrm{c}_{\mathrm{a}}},
$$

where carbon discrimination during $\mathrm{C}_{3}$ photosynthesis depends on a fractionation factor a $(4.4 \%$ ) due to diffusion in air, on net fractionation during $\mathrm{CO}_{2}$ fixation by the RubisCO (b) and on the ratio between $c_{\mathrm{i}}$ (intercellular $\mathrm{CO}_{2}$ concentration) and $c_{\mathrm{a}}$ (ambient $\mathrm{CO}_{2}$ concentration). 
Photosynthetic $\mathrm{CO}_{2}$ discrimination was determined from $c_{\mathrm{i}} / c_{\mathrm{a}}$ according to Eqn (2). In order to be able to calculate $\delta^{13} \mathrm{C}$ values from discrimination, $\delta^{13} \mathrm{C}$ of $\mathrm{CO}_{2}$ in the canopy region was determined twice in the light period during the measurement campaign. The mean value amounted to $-7.9 \%$.

\section{Collection of phloem sap, extraction of water soluble carbon in needles and determination of starch concentration}

Bark pieces from twigs and stems were washed immediately after harvesting with double demineralized water and placed in $6 \mathrm{~mL}$ vials containing $2 \mathrm{~mL}$ of demineralized water as exudation solution and left for $5 \mathrm{~h}$ as described by Rennenberg et al. (1996). Gessler et al. (2004) compared in detail different techniques for collecting phloem sap for isotope analyses. The authors concluded that exudation of the contents of sieve tube cells into demineralized water was the most suitable technique for assessing both, $\delta^{13} \mathrm{C}$ and $\delta^{18} \mathrm{O}$, in phloem organic matter. Previous studies using the exudation technique with different tree species (Schneider et al., 1996) showed how contamination of phloem exudates with cellular constituents could be minimized using simple precautionary steps.

Fresh, frozen leaf samples were homogenized with a mortar and pestle in liquid $N_{2}$. For the extraction of the water-soluble fraction from the needles, $100 \mathrm{mg}$ of homogenized leaf samples were incubated for $60 \mathrm{~min}$ at $5{ }^{\circ} \mathrm{C}$ in $1.5 \mathrm{~mL}$ demineralized water. The extracts were heated at $100{ }^{\circ} \mathrm{C}$ for $3 \mathrm{~min}$ to precipitate proteins and centrifuged ( $12000 \mathrm{~g}$ for $5 \mathrm{~min}$ ). The supernatants were used for isotope analysis.

Starch was determined in frozen fresh current year needle material of one tree using a commercially available kit for starch analysis ('Starch UV-Method' cat. No. 0207748; Boehringer-Mannheim/Roche R-Biopharm AG, Darmstadt; Germany). Starch in the samples was solubilized in dimethylsulfoxide and $\mathrm{HCl}$ and hydrolysed to D-glucose at $\mathrm{pH} 4.6$ in the presence of the enzyme amyloglucosidase. The D-glucose formed is determined with hexokinase and glucose-6-phosphate dehydrogenase (G6P-DH) at pH 7.6. D-Glucose is phosphorylated to D-glucose-6-phosphate by ATP in the presence of hexokinase. In the presence of G6P-DH, D-glucose-6-phosphate is oxidized by NADP to D-gluconate-6-phosphate with the formation of reduced NADPH. The amount of NADPH formed in the above reaction is stoichiometric to the amount of D-glucose formed by hydrolysis of starch. NADPH is determined by means of its light absorbance at $340 \mathrm{~nm}$. From all days of the measurement campaign, the morning, midday, evening and night values of starch concentrations were averaged.
Collection of $\mathrm{CO}_{2}$ emitted from stems for the determination of carbon isotope composition

Clear perspex chambers (approximate dimensions $150 \mathrm{~mm} \times 150 \mathrm{~mm} \times 100 \mathrm{~mm}$ ) were sealed (Terrostat VII; Henkel Teroson GmbH, Heidelberg, Germany) to the trunks (approximately 1.5 and $6.0 \mathrm{~m}$ heights) of the same four trees sampled for needles, twigs and phloem (eight chambers in total). The chambers remained fixed with a strap to the trees throughout the campaign and were sealed airtight with rubber septa only during gas sampling periods. To thoroughly mix air a small circulation fan inside the chambers was activated during sampling periods, while paper-backed aluminium foil shielded chambers from direct sunlight. The chamber space was continuous with a closed system infrared gas analyzer (EGM 4; PPSystems, Hitchin, Hertfordshire, UK) enabling the $\mathrm{CO}_{2}$ concentration to be determined. Sampling was performed every day between 10:00 and 14:00 hours. At each sampling the chamber seal was tested by exhaling around the tree-chamber seal. The ${ }^{13} \mathrm{C}$ isotopic composition of $\mathrm{CO}_{2}$ in air released from stems was determined by a Keeling Plot approach as follows. Within $1 \mathrm{~min}$ of closing the chamber the first of five samples was withdrawn using a plastic $12 \mathrm{~mL}$ syringe and transferred $(10 \mathrm{~mL})$ to a $\mathrm{CO}_{2}$ free $\left(N_{2}\right.$ flushed) sample vials (Exetainer, Labco Ltd, High Wycombe, UK). Samples were withdrawn from the closed chambers at ca. 100 ppm intervals; sampling was usually complete within $5 \mathrm{~min}$ from chamber closure. The $\delta^{13} \mathrm{C}$ of the emitted $\mathrm{CO}_{2}$ was reported as the intercept of the linear regression between $\delta^{13} \mathrm{C}$ of the samples and the inverse of the $\mathrm{CO}_{2}$ concentration at which the sample was collected (based on the mixing model of Keeling, 1958).

\section{Isotope analysis}

For $\delta^{13} \mathrm{C}$ analysis, $100 \mu \mathrm{L}$ of leaf extracts and of phloem exudates were transferred into tin capsules (IVA Analysentechnik, Meerbusch, Germany). The samples contained, on average, ca. $400 \mu \mathrm{g}$ organic C. For $\delta^{18} \mathrm{O}$ analysis, $75 \mu \mathrm{L}$ of phloem exudates were filled into silver capsules (IVA Analysentechnik, Meerbusch, Germany). Water was evaporated at $60^{\circ} \mathrm{C}$ over a period of $12 \mathrm{~h}$. $0.5 \mathrm{mg}$ of homogenized dried bulk leaf material was transferred into tin capsules for $\delta^{13} \mathrm{C}$ analysis. The dried samples were inserted into an elemental analyser (NA 2500; CE Instruments, Milan, Italy) for $\delta^{13} \mathrm{C}$ and into a high temperature conversion/elemental analyser (TC/EA ThermoFinnigan GmbH, Bremen, Germany) for $\delta^{18} \mathrm{O}$ analysis, both coupled to an isotope ratio mass spectrometer (Delta Plus/Delta Plus XL; Finnigan MAT $\mathrm{GmbH}$, Bremen, Germany) by a Conflo II/III interface (ThermoFinnigan $\mathrm{GmbH}$ ). 
$\delta^{13} \mathrm{C}$ of $\mathrm{CO}_{2}$ was determined with a GC/IRMS (GC, Hewlett Packard 5890 series II; IRMS, Finnigan Delta Plus) operating in continuous flow mode. Samples were manually injected into a six-way Valco valve fitted with a $150 \mu \mathrm{L}$ sample loop. $\mathrm{CO}_{2}$ was separated with a $\mathrm{He}$ carrier gas stream from other gaseous constituents of the air using a CarboPlot column. Gas chromatographic separation was achieved at a constant oven temperature of $30^{\circ} \mathrm{C}$ and a flow rate of $2 \mathrm{~mL} \mathrm{~min}^{-1}$. The GC was connected to an isotope mass spectrometer using a modified GC combustion interface (ThermoFinnigan $\mathrm{GmbH})$.

The isotopic values are expressed in delta notation (in $\%$ units), relative to VPDB (Vienna Pee Dee Belemnite) for carbon and VSMOW (Vienna Standard Mean Ocean Water) for oxygen.

\section{Validation experiments}

The LAI of the studied forest is very low, and, consequently the short and sparse crown of the pine trees was not divided into sections (e.g. sun and shade), as has been the practise of other analyses of canopy photosynthesis. Instead, each tree crown was treated as a single unit and sample twigs were chosen accordingly and assumed to adequately represent conditions (of light, humidity etc.) throughout the canopy. We tested the validity of this assumption by conducting an initial sampling at three heights (upper, middle and lower third of the crown) within the canopy. We determined $\delta^{13} \mathrm{C}$ in the water-soluble fraction to assess the nature (if any) of intracanopy $\delta^{13} \mathrm{C}$ gradients because of varying influences of stomatal conductance, assimilation rates or other factors. In addition, we compared stomatal conductance determined on the leaf level $\left(g_{\mathrm{s}}\right)$ with canopy stomatal conductance $\left(G_{s}\right)$ in order to check for scaling errors.

In another validation approach, we compared daynight variations in $\delta^{13} \mathrm{C}$ of the water-soluble carbon fraction and of purified soluble sugars (neutral fraction) extracted from needles. To obtain the soluble sugar fraction, aliquots of the supernatants from water extracts were mixed with Dowex-50( $\left.\mathrm{H}^{+}\right)$and Dowex-1 $\left(\mathrm{Cl}^{-}\right)$in sequence in order to remove contaminating amino acids and organic acids. Resultant eluates contain mainly soluble sugars (Brugnoli et al., 1988; $\mathrm{Xu}$ et al., 2004).

\section{Statistical procedures}

All statistical analyses were performed using NCSS 2004 (Number Cruncher Statistical Software, Kaysville, UT, USA). Differences between $\delta^{13} \mathrm{C}$ and $\delta^{18} \mathrm{O}$ in different chemical fractions or different positions were deter- mined using analysis of variance (ANOVA). Correlations between $\delta^{13} \mathrm{C}, \delta^{18} \mathrm{O}$ and environmental parameters were calculated using the bivariate correlation procedure. Significance of correlation has been calculated according to Sachs (1984). Regression lines between $\delta^{13} \mathrm{C}$ and $\delta^{18} \mathrm{O}$ were determined by linear regression analysis. In order to estimate potential time lags between two variables $(X, Y)$, cross-correlation procedures were performed. The cross-correlation between $X_{t}$ and $Y_{t+k}$ is called the $k^{\text {th }}$ order cross-correlation of $X$ and $Y$. The sample estimate $r_{K}$ of the cross-correlation is calculated using the following equation (Kendall \& Ord, 1990; Newton, 1996):

$$
r_{k}=\frac{\sum_{i=1}^{n-k}\left(X_{i}-\bar{X}\right)\left(Y_{i+k}-\bar{Y}\right)}{\sqrt{\sum_{i=1}^{n}\left(X_{i}-\bar{X}\right)^{2} \sum_{i=1}^{n}\left(Y_{i}-\bar{Y}\right)^{2}}},
$$

where $\bar{X}=\frac{1}{n} \sum_{i=1}^{n} X_{i}$ and $\bar{Y}=\frac{1}{n} \sum_{i=1}^{n} Y_{i}$. Cross-correlations were calculated for daily mean values, and hence, the time (lag) index $k$ has the unit 'day' or they were calculated for the single time points. However, for the latter case the time-differences between the data were not exactly equally spaced. Thus, we assumed the four measurements performed over each $24 \mathrm{~h}$ to be representative for (1) morning, (2) midday/afternoon, (3) evening and (4) night. A time lag of (e.g. $k=1$, means a shift from (i) to $(i+1) ; i$ in $\{1,2,3,4\})$. For $k=4$ the time lag is then 1 day.

In order to assess if a dataset contains a periodic component a periodogram was calculated using the spectral analysis function of NCSS 2004. For the spectral analysis, we again divided the day into four sections (morning, midday/afternoon, evening, night) to arrange the data in form of a time series. Equation (4), which is written in form of a multiple regression, describes the model for the periodic component with a sum of $k$ frequencies:

$$
X_{t}=\sum_{j=1}^{k} a_{j} W_{t j}+\sum_{j=1}^{k} b_{j} Z_{t j}+e_{t},
$$

where $\quad a_{j}=R_{j} \cos \left(d_{j}\right), b_{j}=-R_{j} \sin \left(d_{j}\right), W_{t j}=\cos \left(f_{j} t\right), Z_{t j}=$ $\sin \left(\mathrm{f}_{\mathrm{j}} \mathrm{t}\right)$, where $R$ is the amplitude of the variation, $f$ is the frequency of the periodic variation measured in numbers of radians per unit time, $d$ is the phase, $e_{t}$ is the random error (noise) of the series, $t$ is the time period number.

Consequently, Eqn (4) can also be expressed as follows:

$$
X_{t}=\sum_{j=1}^{k} R_{j} \cos \left(f_{j} t+d_{j}\right)+e_{t} .
$$

For the spectral analysis, the total sum of squares as a measure for the variation is separated into amounts 
associated with each frequency (or wavelength $=2 \pi / f$ ). The sum of squares of a particular frequency as a proportion of the total sum of squares in an appropriate frequency range $(N=35)\left(I\left(f_{k}\right)\right)$ is:

$$
I\left(f_{k}\right)=\frac{N}{4 \pi}\left(a_{k}^{2}+b_{k}^{2}\right) \text {. }
$$

The periodogram was corrected for series average and trend.

\section{Results}

\section{Validation experiments}

There was no intracanopy gradient of $\delta^{13} \mathrm{C}$ in the watersoluble fraction (Table 1). Together with the high and significant regression coefficient obtained for the relation between canopy stomatal conductance and leaf level stomatal conductance (Fig. S1) we contend that the twigs selected for the assessment of diel courses of gas exchange parameters and isotopic signatures were representative for the whole canopy. This is a prerequisite for a comparison of leaf level $\left(\mathrm{A}, c_{\mathrm{i}} / c_{\mathrm{a}}\right.$, foliar $\left.\delta^{13} \mathrm{C}\right)$ with canopy integrating parameters $\left(G_{\mathrm{s}}\right.$ phloem $\delta^{13} \mathrm{C}$ ).

$\delta^{13} \mathrm{C}$ of the water soluble carbon fraction did not differ significantly from that of the neutral fraction that

Table 1 Carbon isotope signature $\left(\delta^{13} \mathrm{C}\right)$ of water soluble carbon of current and previous year's needles collected in the upper, middle and lower third of the canopy

\begin{tabular}{|c|c|c|}
\hline Canopy position & $\begin{array}{l}\delta^{13} \mathrm{C}(\%) \text { in previous } \\
\text { year needles }\end{array}$ & $\begin{array}{l}\delta^{13} \mathrm{C}(\%) \text { in current } \\
\text { year needles }\end{array}$ \\
\hline Upper canopy & $-27.39 \pm 0.25 a$ & $-26.69 \pm 1.14 a$ \\
\hline Middle canopy & $-26.74 \pm 0.81 a$ & $-26.31 \pm 0.47 a$ \\
\hline Lower canopy & $-26.87 \pm 0.80 \mathrm{a}$ & $-26.38 \pm 0.19 a$ \\
\hline
\end{tabular}

Data shown are mean values \pm SD from four different trees. Values in columns that share a common letter are not significantly different at a $95 \%$ significance level. represents soluble sugars (Table 2) suggesting that amino compounds and organic acids had either low concentrations or their carbon isotope signature was similar compared with sugars. We can, thus, assume that the influence of organic acids and other ionic compounds on $\delta^{13} \mathrm{C}$ of the water soluble fraction is negligible and exclude the possibility that strong daynight changes in concentrations of such compounds that might differ from sugars in their carbon isotope composition - are responsible for variations in $\delta^{13} \mathrm{C}$ of water soluble carbon.

\section{Meteorological and gas exchange parameters}

Figure 1 shows meteorological parameters as well as stand transpiration and canopy stomatal conductance during the measurement campaign. The daily temperature amplitude was slightly smaller during the measurement campaign than the immediately preceding period. Maximum daily VPD ranged between 800 and $2500 \mathrm{~Pa}$ and was least on the 7th and 8th July - days on which significant rainfall was recorded. The night of the 5th saw additional rainfall of $14.4 \mathrm{~mm}$. Whereas, three days before the measurement campaign the forest was exposed to full sunlight with maximum PAR up to $1850 \mu \mathrm{mol} \mathrm{m}^{-2} \mathrm{~s}^{-1}$ and mean PAR during the light period of $850-950 \mu \mathrm{mol} \mathrm{m}^{-2} \mathrm{~s}^{-1}$, mean radiation interception during the first 2 and the last 3 days of the measurement campaign was only half that, and the least daytime radiation input (maximum PAR: $706 \mu \mathrm{mol} \mathrm{m}^{-2} \mathrm{~s}^{-1}$; mean daytime PAR: $245 \mu \mathrm{mol} \mathrm{m}^{-2} \mathrm{~s}^{-1}$ ) was recorded on the 5 th July. Diel patterns of stand transpiration and $G_{\mathrm{s}}$ were comparable during the 5 days preceding the measurement campaign. Starting from the 1st of July, total daily transpiration decreased to ca. $0.95 \mathrm{~mm}$ during the first 4 days of the measurement campaign and reached a minimum of $0.4 \mathrm{~mm}$ on the 8 th July. Stomatal conductance between the 1st and the 9th July was about half that recorded during the 5 preceding days, with the exception of the

Table 2 Carbon isotope signature $\left(\delta^{13} \mathrm{C}\right.$ in \%) of water soluble carbon and of the (neutral) soluble sugar fraction of current and previous year's needles collected at one time point during day or night

\begin{tabular}{llllll}
\hline & \multicolumn{2}{l}{ Previous year needles } & & & \multicolumn{2}{c}{ Current year needles } \\
\cline { 2 - 3 } & Water soluble fraction & Soluble sugar fraction & & Water soluble fraction & Soluble sugar fraction \\
\hline Day & $-26.81 \pm 0.36 \mathrm{a}$ & $-27.02 \pm 0.42 \mathrm{a}$ & & $-26.27 \pm 0.99 \mathrm{a}$ & $-26.89 \pm 0.66 \mathrm{a}$ \\
Night & $-26.60 \pm 0.69 \mathrm{a}$ & $-26.43 \pm 0.33 \mathrm{a}$ & & $-27.59 \pm 0.96 \mathrm{a}$ & $-27.48 \pm 0.87 \mathrm{a}$ \\
\hline
\end{tabular}

When the $\delta^{13} \mathrm{C}$ value of the water soluble fraction shares a common letter with the value of the sugar fraction they are not significantly different at a $95 \%$ significance level.

Data shown are mean values \pm SD from four different trees. 
6th and the 8th July. However, during these 2 days, rainfall events increased $\mathrm{RH}$ to almost $100 \%$. Under these conditions, the application of the inverted Penman-Monteith model as shown in Eqn (1) may result in an overestimation of $G_{\mathrm{s}}$ (Keitel et al., 2003).

Net $\mathrm{CO}_{2}$ assimilation at the leaf level in the light showed diel, as well as day-to-day variation during the measurement period whereas $c_{\mathrm{i}} / c_{\mathrm{a}}$ was more constant (Fig. 2A). We obtained a typical light response curve for $A$ by plotting both parameters against PAR (also measured at the leaf level; Fig. 2B). A nonlinear, curvefitting procedure with an exponential model $(A=a$ $\left[1-b^{\mathrm{PAR}}\right]$ ) produced an $R^{2}$ of 0.94 . Calculated maximum net assimilation at light saturation $\left(A_{\max }\right)$ was ca. $3.81 \mu \mathrm{mol} \mathrm{m}^{-2} \mathrm{~s}^{-1}$. Saturation was achieved at ca. $500 \mu \mathrm{mol} \mathrm{m}^{-2} \mathrm{~s}^{-1}$. Hence, variation in $A$ as shown in Fig. $2 \mathrm{~A}$ is due to the variation of PAR input at the time of measurement. $c_{\mathrm{i}} / c_{\mathrm{a}}$ was constant at approximately 0.65 in a PAR range between 400 and $1600 \mu \mathrm{mol} \mathrm{m}^{-2} \mathrm{~s}^{-1}$ and generally increased up to 0.7 at reduced light intensities and, thus, lesser $A$.

\section{Starch concentration in current year needles}

There was a distinct diel course of starch concentration in the current year needles (Fig. S2). The average starch concentration in the morning (08:00-10:00 hours) amounted to $3.2 \mathrm{mg} \mathrm{g}^{-1} \mathrm{FW}$ and increased to $5.1 \mathrm{mg} \mathrm{g}^{-1}$ FW in the evening. During night (22:00-01:00 hours) the 9 day average starch concentration decreased to ca. $4 \mathrm{mg} \mathrm{g}^{-1} \mathrm{FW}$.

\section{Carbon isotope signatures of leaf and phloem organic matter}

The carbon isotope signature of water soluble organic matter showed clear diel patterns in current and previous year's needles within the first 5 days of measurement (Fig. 3A). This carbon fraction was most depleted in ${ }^{13} \mathrm{C}$ during afternoons and evenings, reaching values as low as $-27.3 \%$ (current year's needles). The same fraction was relatively enriched at night and/or in the morning. The maximum $\delta^{13} \mathrm{C}$ recorded was $-25.8 \%$ giving a maximum diel range of $1.5 \%$ during this period. After rainfall, these diel patterns disappeared and there were consequent reductions in $\delta^{13} \mathrm{C}$.

In contrast, $\delta^{13} \mathrm{C}$ signatures of total leaf carbon did not display distinct diel fluctuations and did not show clear, longer-term trends during the 9 days of measurement (Fig. 3B). Whereas mean $\delta^{13} \mathrm{C}$ signatures over the whole measurement campaign were almost identical for water soluble and total carbon in previous year's needles $(-26.7 \%)$, total carbon was enriched $(-26.1 \%)$ compared with the water-soluble fraction $(-26.7 \%)$ in cur-

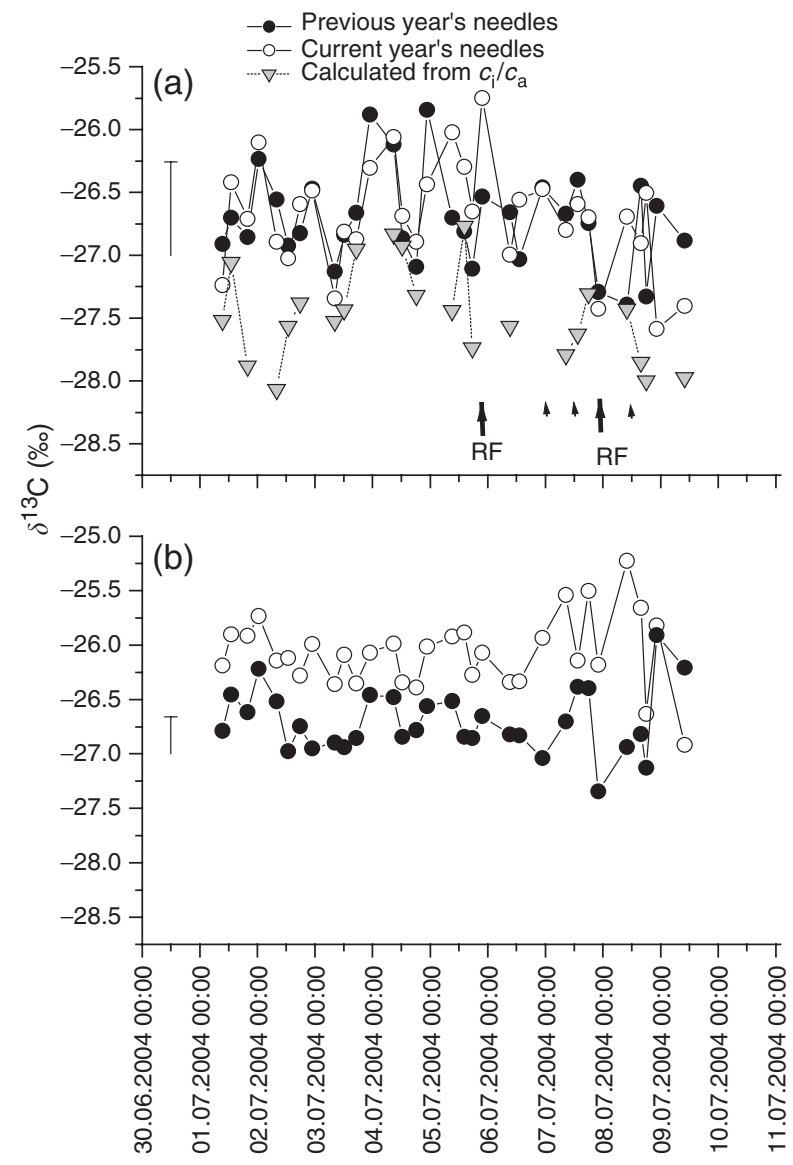

Fig. 3 Carbon isotope signature $\left(\delta^{13} \mathrm{C}\right)$ of water soluble (a) and total carbon (b) of current and previous year's needles. Data shown are mean values from four different trees. In addition, the average standard deviation for the mean values is given. $R F$, start of a rainfall event (bold arrows: intensity $>1.5 \mathrm{~mm} \mathrm{~h}^{-1}$, small arrows intensity $<1.5 \mathrm{~mm} \mathrm{~h}^{-1}$ ). Calculation of $\delta^{13} \mathrm{C}$ as shown in (a) was performed according to Eqn (2) and assuming a constant $\delta^{13} \mathrm{C}$ of tropospheric $\mathrm{CO}_{2}$ during the day of $7.9 \%$.

rent year's needles. $\delta^{13} \mathrm{C}$ calculated from $c_{\mathrm{i}} / c_{\mathrm{a}}$ according to Eqn (2) and by assuming a constant $\delta^{13} \mathrm{C}(7.9 \%)$ of the $\mathrm{CO}_{2}$ fixed by the needles, ranged between $-26.8 \%$ and $-28.1 \%$ (Fig. 3A). Thus, calculated $\delta^{13} \mathrm{C}$ was in general more negative compared with actual $\delta^{13} \mathrm{C}$ measured for total and water-soluble carbon pools.

Carbon isotope signatures in the twig phloem showed - comparable with the water-soluble carbon in the foliage - clear diel courses within the period before rainfall events (Fig. 4A). Phloem carbon was least depleted in ${ }^{13} \mathrm{C}$ at night or in the morning and maximum depletion was recorded in the afternoon/ evening. The strongest ${ }^{13} \mathrm{C}$ enrichment $(-24.5 \%$ ) was observed in the morning of 1st July. Comparable clear diel rhythms were not found in the phloem of the stem, independent of the sampling position. Patterns of 


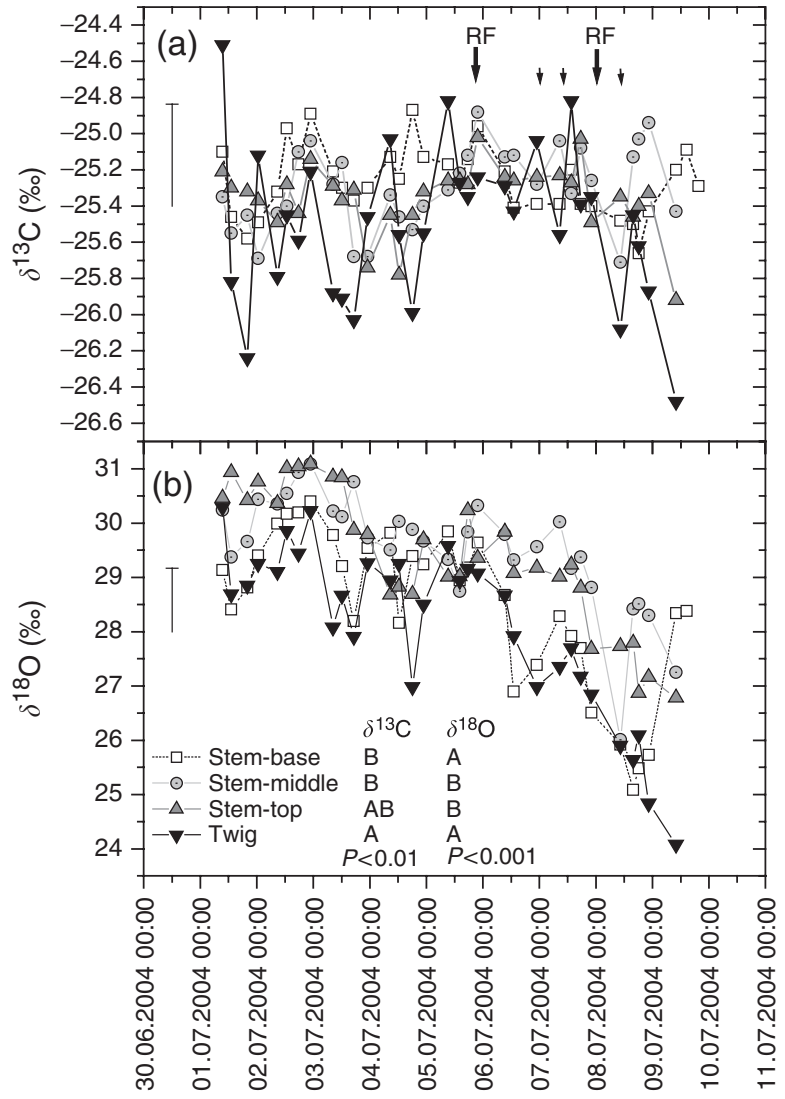

Fig. 4 Carbon $\left(\delta^{13} \mathrm{C}\right.$; a) and oxygen isotope $\left(\delta^{18} \mathrm{O} ; \mathrm{b}\right)$ signature of phloem organic matter. Data shown are mean values from the phloem of twigs and stem (top, middle, base) of four different trees. In addition, the average standard deviation for the mean values is given. $\mathrm{RF}$, start of a rainfall event (bold arrows: intensity $>1.5 \mathrm{~mm} \mathrm{~h}^{-1}$, small arrows intensity $<1.5 \mathrm{~mm} \mathrm{~h}^{-1}$ ). Different letters indicate significant differences for $\delta^{13} \mathrm{C}$ and $\delta^{18} \mathrm{O}$ between different position (twig; stem-top; stem-middle; stem-base) during the whole measurement period applying an ANOVA procedure with a Tukey-Cramer post hoc test.

variation in $\delta^{13} \mathrm{C}$ were characterized by: (1) smaller amplitudes compared with twig phloem; and (2) maxima and minima not being related to the day-night rhythm.

After the first rainfall event, we recorded the disappearance of the previously observed diel pattern in $\delta^{13} \mathrm{C}$ of the twig phloem. There was, however, no general trend of increasing or decreasing phloem $\delta^{13} \mathrm{C}$ in either twigs or stem as a consequence of the change in weather conditions. After the second, somewhat heavier precipitation event, $\delta^{13} \mathrm{C}$ in the twig phloem decreased from $-25.5 \%$ (8 July 2005 15:50 hours) to $-26.5 \%$ (9 July 2005 10:00 hours). A comparable decrease was observed in the phloem of the upper and middle stem, with a time lag of some hours (decrease between 8 July 2005 22:20 hours and 9 July 2005 10:00 hours) and in the phloem of the stem base ca. $24 \mathrm{~h}$ later. In general - when the whole measurement period was taken into account - phloem carbon in the twigs was depleted $(P<0.01)$ relative to carbon from the middle and the lower part of the stem. Water-soluble carbon extracted from foliage was, on the other hand, significantly $(P<0.001)$ depleted in ${ }^{13} \mathrm{C}$ as compared with twig phloem organic matter. At each time point, $\delta^{13} \mathrm{C}$ of twig phloem was between $0.5 \%$ and $2.7 \%$ greater than that of the soluble organic matter fraction in the foliage.

\section{Oxygen isotope signatures of phloem organic matter}

Oxygen isotope signatures of phloem organic matter decreased from the beginning to the end of the measurement campaign (Fig. 4B). This was most pronounced for twig phloem (from 30.3\% at 09:30 hours on the 1 July to $24.1 \%$ at $10: 00$ hours on the 9 July). At all sampling positions, $\delta^{18} \mathrm{O}$ of phloem organic matter decreased rapidly after rainfall by up to $4.9 \%$ (twig), 2.6\% (stem-top), 3.1\%o (stem-middle) and 4.6\%o (stembase). There were significant differences in $\delta^{18} \mathrm{O}$ of organic matter between twig phloem and the phloem of the top and the middle of the stem. For nearly all time points, organic matter was less enriched in ${ }^{18} \mathrm{O}$ in the twig phloem compared with the two upper positions of the stem.

\section{Correlation and spectral analyses}

There were no strong or even moderate $(R \geq 0.5)$ correlations among carbon or oxygen isotope signatures in phloem or leaf organic matter and meteorological or gas exchange parameters. The only significant correlations were between $\delta^{13} \mathrm{C}$ in the water soluble carbon fraction of current year's needles and $c_{\mathrm{i}} / c_{\mathrm{a}} \quad(R=-0.413$; $P=0.049)$, and between $\delta^{18} \mathrm{O}$ of the twig phloem organic matter and RH $(R=-0.416 ; P=0.043)$. Table 3 shows the significant Pearson's correlation coefficients $\geq 0.5$ among $\delta^{13} \mathrm{C}$ and $\delta^{18} \mathrm{O}$ values of different tissues (needles, phloem) and different sampling positions. Again, $\delta^{13} \mathrm{C}$ signatures of leaves and phloem organic matter were not significantly related. In contrast, $\delta^{18} \mathrm{O}$ of twig phloem organic matter was highly correlated with $\delta^{18} \mathrm{O}$ of stem phloem at all positions. As a consequence, this parameter was highly and significantly correlated among different sampling positions along the stem. In addition, $\delta^{13} \mathrm{C}$ was moderately correlated with $\delta^{18} \mathrm{O}$ in organic matter transported in the phloem of the stem base. The application of cross-correlation analysis, including time lags up to $k=20$ (5 days) did not change the patterns observed (data not shown). 
Table 3 Correlation between $\delta^{13} \mathrm{C}$ and $\delta^{18} \mathrm{O}$ of organic matter in the phloem at different positions (twig, upper stem, middle stem, stem base)

\begin{tabular}{|c|c|c|c|c|}
\hline & $\begin{array}{l}\delta^{13} \mathrm{C} \text { phloem - } \\
\text { stem base }\end{array}$ & $\begin{array}{l}\delta^{18} \mathrm{O} \text { phloem - } \\
\text { twig }\end{array}$ & $\begin{array}{l}\delta^{18} \mathrm{O} \text { phloem - } \\
\text { stem top }\end{array}$ & $\begin{array}{l}\delta^{18} \mathrm{O} \text { phloem - } \\
\text { stem middle }\end{array}$ \\
\hline$\delta^{18} \mathrm{O}$ phloem - stem top & & $\begin{array}{r}\mathbf{0 . 8 2 4} \\
<0.001\end{array}$ & - & - \\
\hline$\delta^{18} \mathrm{O}$ phloem - stem middle & & $\begin{array}{r}\mathbf{0 . 7 5 2} \\
<0.001\end{array}$ & $\begin{array}{r}0.781 \\
<0.001\end{array}$ & - \\
\hline$\delta^{18} \mathrm{O}$ phloem - stem base & $\begin{array}{r}\mathbf{0 . 6 7 5} \\
<0.001\end{array}$ & $\begin{array}{r}\mathbf{0 . 7 7 1} \\
<0.001\end{array}$ & $\begin{array}{r}\mathbf{0 . 7 7 1} \\
<0.001\end{array}$ & $\begin{array}{r}\mathbf{0 . 6 9 4} \\
<0.001\end{array}$ \\
\hline
\end{tabular}

Bold figures are Pearson's correlation coefficients $(R)$, figures in italics show the significance level. Results are only shown when $R \geq 0.5$

Figures 3 and 4 suggest that - at least during the first 5 days and in contrast to $\delta^{18} \mathrm{O}-\delta^{13} \mathrm{C}$ of water soluble carbon in leaf tissue and twig phloem display comparable diel rhythms. However, the diel amplitude was highly variable among days and the day-to-day change was not consistent in leaves and twig phloem. In order to quantitatively assess common periodicity of $\delta^{13} \mathrm{C}$ among different carbon pools, we used a spectral data analysis. Judging by a relatively high value of $I(f)$ in the periodogram (Fig. 5), we see a periodicity with a wavelength of 4.5 for $\delta^{13} \mathrm{C}$ in the foliar water soluble fraction. In this study, each $24 \mathrm{~h}$ period consisted of four measurements (morning; midday/afternoon, evening, night). The data thus suggest a cyclic pattern with a wavelength slightly greater than 1 day, throughout the measurement campaign. There is also a maximum for $I(f)$ at a wavelength of ca. 4.4 for $\delta^{13} \mathrm{C}$ of twig phloem (Fig. 5). However, this peak is less prominent compared with that ascribed to leaves, indicating a consequently less strong periodic component in the data set for twig phloem. The even distribution of $I(f)$ for $\delta^{13} \mathrm{C}$ in the upper stem phloem indicates the lack of a periodic component in this data set (Fig. 5).

\section{Daily mean values}

Daily mean values were calculated in order to characterize day-to-day variations in isotope signatures and then relate them to potential influencing factors. Daily means were related to daily average climatic and gas exchange parameters during the light period. $c_{\mathrm{i}} / c_{\mathrm{a}}$ and $G_{S}$ were weighted by A according to Cernusak et al. (2005). There was a strong and significant correlation between $c_{\mathrm{i}} / c_{\mathrm{a}}$ and $\delta^{13} \mathrm{C}$ in the water-soluble carbon fraction of current year needles (Table 4). Regression analysis between $c_{\mathrm{i}} / c_{\mathrm{a}}$ and $\delta^{13} \mathrm{C}$ produced a line characterized by the linear equation: $\delta^{13} \mathrm{C}(\%)=-21.1(\%)$ $c_{\mathrm{i}} / c_{\mathrm{a}}-12.6$ (\%) (Fig. S3). The relation was not significant for older needles (Table S1; Table 4 only shows the

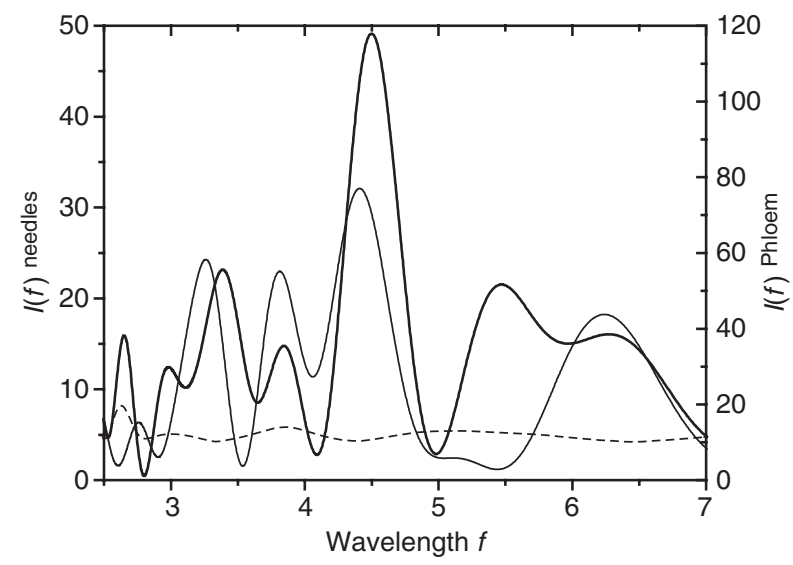

Fig. 5 Periodogram in the wavelength scale for time series scaled $\delta^{13} \mathrm{C}$ in the water-soluble carbon fraction of current year's needles (bold line), in the phloem organic matter of twigs (solid line) and in the phloem organic of the upper stem phloem (dotted line). For the spectral analysis the day was divided into four sections (morning, midday/afternoon, evening, night) to arrange the data in form of a time series. Thus, a wavelength of 4 refers to 1 day. Note that $I(f)$ is dimensionless.

significant correlation coefficients. All correlation coefficients for the relations between daily means of $\delta^{13} \mathrm{C}$ and $\delta^{18} \mathrm{O}$ and daily averages of climatic and gas exchange parameters are given in Table S1 and for correlations between $\delta^{13} \mathrm{C}$ and $\delta^{18} \mathrm{O}$ at different positions along the tree axis in Table S2 in the Supplementary Material). The correlation coefficient was still moderate $(-0.623)$, albeit not significant, for the relation between $c_{\mathrm{i}} / c_{\mathrm{a}}$ and $\delta^{13} \mathrm{C}$ of twig phloem and declined to -0.047 for $\delta^{13} \mathrm{C}$ of the mid stem. No other environmental or gas exchange parameter showed significant correlation to $\delta^{13} \mathrm{C}$ in different tissues. $\delta^{18} \mathrm{O}$ signatures of phloem organic matter from twigs were highly and significantly correlated with photosynthesis-weighted stomatal conductance, but correlation coefficients became insignificant when stem phloem values were used for analysis 
(Table S1). All other climatic or gas exchange parameters $\left(c_{\mathrm{i}} / c_{\mathrm{a}}, \mathrm{A}, \mathrm{PAR}\right.$, air temperature and transpiration) did not produce significant correlation with $\delta^{18} \mathrm{O}$.

Measures of the strength of the relations between $\delta^{13} \mathrm{C}$ and $\delta^{18} \mathrm{O}$ at different positions along the tree axis are provided in Tables 4 and S2. $\delta^{13} \mathrm{C}$ of phloem organic matter in the twigs was strongly and significantly influenced by $\delta^{13} \mathrm{C}$ of water soluble organic matter of current but not previous year's needles. On the other hand, $\delta^{13} \mathrm{C}$ in the phloem at the stem top was highly correlated with $\delta^{13} \mathrm{C}$ of the twig phloem. Such correlation was not observed at other positions along the stem. Whereas $\delta^{13} \mathrm{C}$ of $\mathrm{CO}_{2}$ emitted from the stem base was correlated with $\delta^{13} \mathrm{C}$ in the phloem organic matter from the middle part of the stem, there was no relation with the phloem $\delta^{13} \mathrm{C}$ at the same position. $\delta^{13} \mathrm{C}$ of respired $\mathrm{CO}_{2}$ from the middle part of the stem was not correlated to the carbon isotope signature of any of the determined water-soluble pools. $\delta^{18} \mathrm{O}$ in phloem allocated organic compounds of the twig was closely related to $\delta^{18} \mathrm{O}$ in the upper and middle stem phloem. There was also a moderate to strong correlation between $\delta^{13} \mathrm{C}$ and $\delta^{18} \mathrm{O}$ in phloem organic matter collected from twigs, upper stem and stem base.

We applied cross-correlation analyses in order to assess time lags in the isotopic signature among different positions along the tree axis. Figure 6A shows that applying a time-difference of 1 day between the $\delta^{13} \mathrm{C}$ values of the water-soluble carbon of current year needles and of the stem base phloem increased the correlation coefficient to 0.87 , whereas $R$ decreased with an increasing time lag for the twig and stem top phloem. Comparable patterns were observed when $\delta^{13} \mathrm{C}$ and $\delta^{18} \mathrm{O}$ of twig phloem were correlated to $\delta^{13} \mathrm{C}$ and $\delta^{18} \mathrm{O}$, respectively, of stem phloem organic matter at different positions. Correlations of twig phloem with top or middle stem phloem produced decreasing $R$ with increasing time difference while the correlation coefficient increased initially for correlation with stem base phloem. There was no significant change in correlation for all other parameters shown in Tables 4 and S2 when potential time lags were taken into account by crosscorrelation analyses.

\section{$\delta^{13} \mathrm{C}$ of $\mathrm{CO}_{2}$ emitted from stems vs. $\delta^{13} \mathrm{C}$ of phloem organic carbon}

In order to estimate if $\mathrm{CO}_{2}$ emitted from the stem was enriched or depleted in ${ }^{13} \mathrm{C}$ as compared with the carbon source supplied (stem phloem), both $\delta^{13} \mathrm{C}$ values were plotted against each other (Fig. 7A, B). At both stem positions, emitted $\mathrm{CO}_{2}$ was enriched compared with phloem organic matter. The enrichment in ${ }^{13} \mathrm{C}$ amounted to between $2.3 \%$ and $5.2 \%$. In general, $\delta^{13} \mathrm{C}$ of $\mathrm{CO}_{2}$ showed higher day-to-day variability compared with the potential carbon source. There were no signs that the isotopic signature of respired $\mathrm{CO}_{2}$ differed among positions along the stem. Plotting $\delta^{13} \mathrm{C}$ values of $\mathrm{CO}_{2}$ emitted from the stem base against values from the middle of the stem resulted in points scattering around the $1: 1$ line (Fig. 7C).

\section{$\delta^{13} \mathrm{C}$ vs. $\delta^{18} \mathrm{O}$ of phloem organic matter}

As shown in Table 4 there was a significant correlation between $\delta^{13} \mathrm{C}$ and $\delta^{18} \mathrm{O}$ in the phloem of the twigs, the upper stem and the stem base. The slope of the regression line between $\delta^{18} \mathrm{O}$ and $\delta^{13} \mathrm{C}$ is required for analysis of the conceptual model proposed by Scheidegger $e t$ al. (2000). Fig. S4 displays the respective regression lines where the slopes amount to $0.08 \% / \%$ for organic matter from the stem base, to $0.11 \% / \%$ for the upper stem and to $0.16 \% / \%$ for the twig phloem. The y-axis offsets range between $-29.97 \%$ and $-27.77 \%$.

\section{Discussion}

In the present study, we aimed to differentiate the effects of photosynthetic and postphotosynthetic carbon isotope discrimination on $\delta^{13} \mathrm{C}$ of the fast-turn-over carbon pool (water soluble organic carbon and $\mathrm{CO}_{2}$ emitted from heterotrophic tissues). We sought to assess the diel variation in these separate influences, as well as how these may vary along the transport pathway, from the foliage to the base of the stem.

\section{Diel variation of $\delta^{13} \mathrm{C}$ in leaves and twig phloem indicate influence of starch storage and remobilization}

We observed repeating diel variations in $\delta^{13} \mathrm{C}$ in total and water soluble carbon pools in leaves and in twig phloem organic matter, especially during the first 5 days when external meteorological conditions were rather constant (Fig. 1). While amplitude varied with time and/or pool, the wavelength of the oscillation was of the order of 1 day in leaves and twig phloem (Fig. 5) organic matter was most enriched (in ${ }^{13} \mathrm{C}$ ) during night/ morning and most depleted during the later light period.

As has been known for some time, export of triosephosphates from the chloroplast can become rate limiting to carbon assimilation, especially under high light and well-watered conditions. Under these conditions, transitory starch accumulates (Beck \& Ziegler, 1989). If triose-phosphates are equilibrated with hexoses by the aldolase-catalysed reaction in the chloroplast, then isotopically heavier hexoses will be incorporated in starch while ${ }^{13} \mathrm{C}$ depleted trioses will be exported to the cytoplasm, because of the aldolase isotope effect 


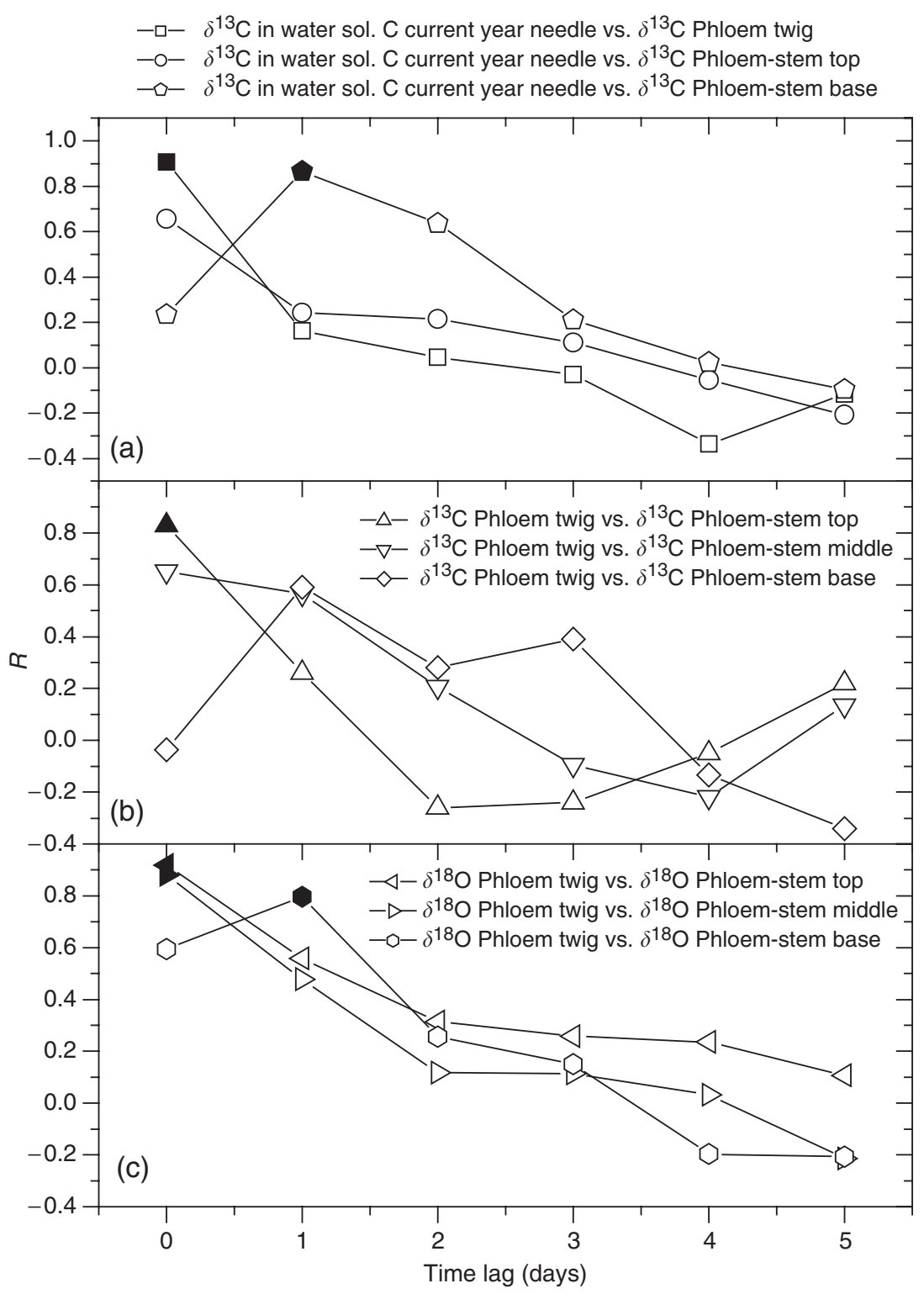

Fig. 6 Correlation coefficients for cross-correlation analysis between $\delta^{13} \mathrm{C}$ in the water soluble fraction of the current year's needles and the organic matter in the phloem at different positions (a) between $\delta^{13} \mathrm{C}$ in the twig phloem and in the stem phloem at different positions (b) and between $\delta^{18} \mathrm{O}$ in the twig and the stem phloem (c). Data shown are daily mean values from measurements with four trees at four time points per day. Black symbols indicate significant correlation $(P<0.05)$.

(Gleixner \& Schmidt, 1997; Gleixner et al., 1998). This process results in isotopic enrichment of chloroplastic starch and depletion of cytosolic carbon during the day (Gleixner et al., 1998). In contrast, when starch is remobilized during the night, sucrose exported from leaves is likely to carry the signature of substrate starch (Tcherkez et al., 2004). Applying a modelling approach, these authors suggested day-night differences in $\delta^{13} \mathrm{C}$ of leaf sucrose could amount to up to $4.4 \%$. In sunflower, Ghashghaie et al. (2001) observed differences in carbon isotope signature of foliar sucrose between light and dark periods of ca. $1 \%$, with $\delta^{13} \mathrm{C}$ values at night being close to those of starch. Our observations of repeated day-night differences in water-soluble carbon of $1.6 \%$ in foliage and 1.9\%o in twig phloem (Figs 3 and 4) fit well with proposed diel cycles of starch storage and decomposition. Support for this contention is further derived from (1) the clear diel course of starch concentration in current year needles and (2) the lack of a diel pattern in $\delta^{18} \mathrm{O}$ signature of twig phloem that might otherwise suggest changes in stomatal conductance were at least partly responsible for oscillation in $\delta^{13} \mathrm{C}$. 

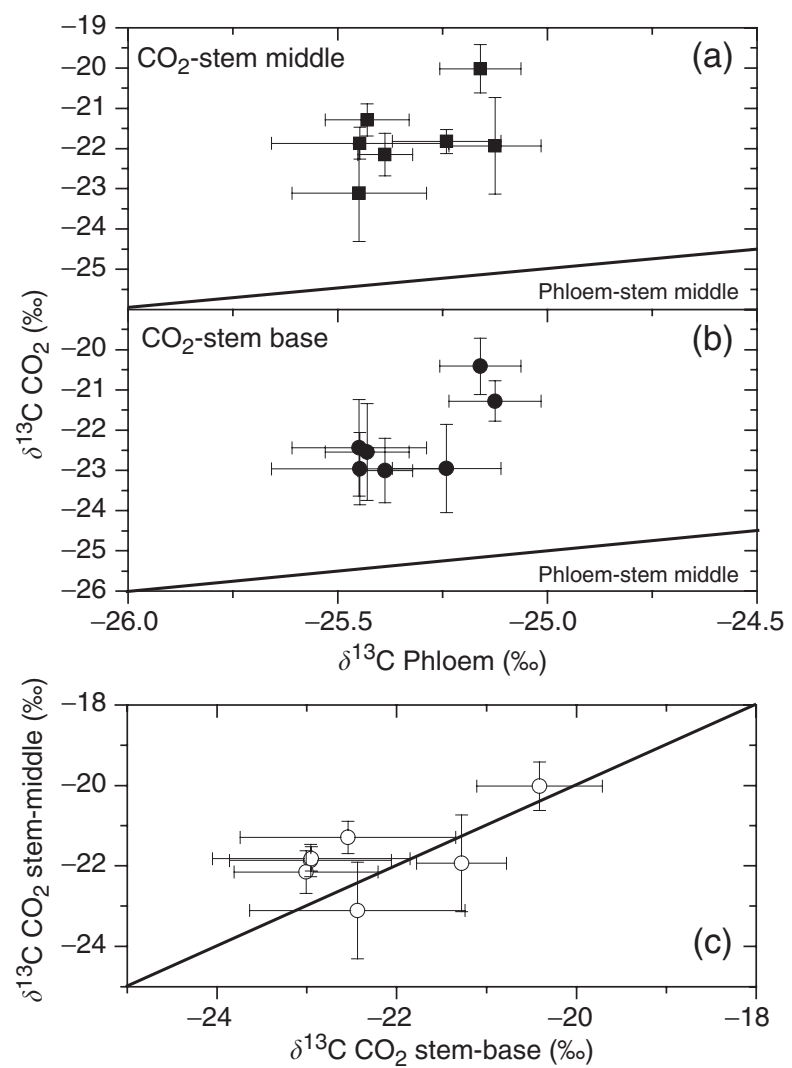

Fig. $7 \quad \delta^{13} \mathrm{C}$ of phloem organic matter (stem middle) plotted against $\delta^{13} \mathrm{C}$ of $\mathrm{CO}_{2}$ emitted from the middle stem (a) and the stem base (b) and the relation between $\delta^{13} \mathrm{C}_{\text {of }} \mathrm{CO}_{2}$ emitted from both positions (c). In (a) and (b) $\delta^{13} \mathrm{C}$ of organic matter from the phloem of the middle stem was chosen as it produced the highest correlation with $\delta^{13} \mathrm{C}$ of $\mathrm{CO}_{2}$ emitted from both positions, stem base and middle stem (Tables 4 and S2). Data shown are daily mean values $\pm \mathrm{SD}$. $\delta^{13} \mathrm{C}$ of phloem organic matter was determined for four trees at four time points per day. $\delta^{13} \mathrm{C}_{\text {of }} \mathrm{CO}_{2}$ is the mean of measurements of three trees.

Furthermore, the distinct day-night differences in phloem sugar $\delta^{13} \mathrm{C}$ indicate restricted exchange of triose-phosphates between the chloroplast and cytoplasm. If this exchange were instead unhindered, aldolase reactions in cytoplasm and chloroplast would use the same pool of triose-phosphates as substrate. We would, thus, expect both starch and light-produced sucrose to have the same isotopic signature (Tcherkez et al., 2004).

${ }^{13} \mathrm{C}$ enrichment from the leaves to the stem base indicates fractionation, associated with metabolic processes in source and sink tissues

Assuming the $\delta^{13} \mathrm{C}$ signature of newly fixed carbon is as calculated from $c_{\mathrm{i}} / c_{\mathrm{a}}$, it is obvious that there are sig- nificant differences between the signatures of primary assimilates and fast-turn-over (water-soluble) and structural carbon (Figs 3 and S3). If the pool of watersoluble carbon is assumed, as defined by Hobbie \& Werner (2004), to represent unreacted carbohydrates (i.e. a steady state pool of carbohydrates that can be used for cellulose synthesis or exported into the phloem), it is plausible that these compounds are isotopically heavier compared with primary assimilates.

Nonexported and ${ }^{13} \mathrm{C}$-depleted compounds like lipids and lignin, are produced from the primary assimilates and accumulate in leaves. When heavier carbon is exported and lighter carbon remains in leaves, total foliar carbon should be ${ }^{13} \mathrm{C}$-depleted by comparison with primary assimilates. Figure 3B shows carbon isotope signatures of current and previous year's needles of $P$. sylvestris. These data suggest new needles are enriched in ${ }^{13} \mathrm{C}$ by almost $1 \%$. Others have noted for trees that newly developed foliage is initially enriched and then continuously depleted until senescence (e.g. Jaggi et al., 2002; Keitel et al., 2003; Helle \& Schleser, 2004). One explanation is that carbon in newly developing leaves mainly originates from remobilized starch with a less negative $\delta^{13} \mathrm{C}$ and is subsequently diluted by lighter carbon from current assimilation (Keitel et al., 2003). However, more intensive lignification and increased stomatal conduction with increasing needle age could also contribute to the observed effect. As $\delta^{13} \mathrm{C}$ depletion is a more or less continuous process during a leaf's lifetime, we can assume that current assimilates are ${ }^{13} \mathrm{C}$ depleted by comparison with total organic carbon (Helle \& Schleser, 2004).

In addition to the ${ }^{13} \mathrm{C}$ enrichment associated with the process of conversion of assimilates into soluble organic carbon in foliage, there is increasing enrichment in the water-soluble fraction in the sequence: leaf tissuetwigs-stem phloem. Damesin \& Lelarge (2003) stated that carbohydrates like sucrose become isotopically heavier during the leaf-to-stem transition. In addition, Badeck et al. (2005) reviewed more than 80 publications for differences in $\delta^{13} \mathrm{C}$ signatures between organs and showed clearly that below-ground tissues are generally enriched in ${ }^{13} \mathrm{C}$, compared with above-ground organs. Hobbie \& Werner (2004) and Cernusak et al. (2005) proposed that the main carbon fractionation processes responsible for such differences remain in autotrophic tissues and are dominated by loading ${ }^{13} \mathrm{C}$ enriched sugars from the unreacted sugar pool into the sieve tubes. In contrast, Terwilliger et al. (2001) and Helle \& Schleser (2004) proposed that the ${ }^{13} \mathrm{C}$ enrichment of organic matter in organs that lacked autotrophic capacity was a result of either fractionation processes or an increased proportion of PEP-carboxylase fixed carbon in these sink tissues. 


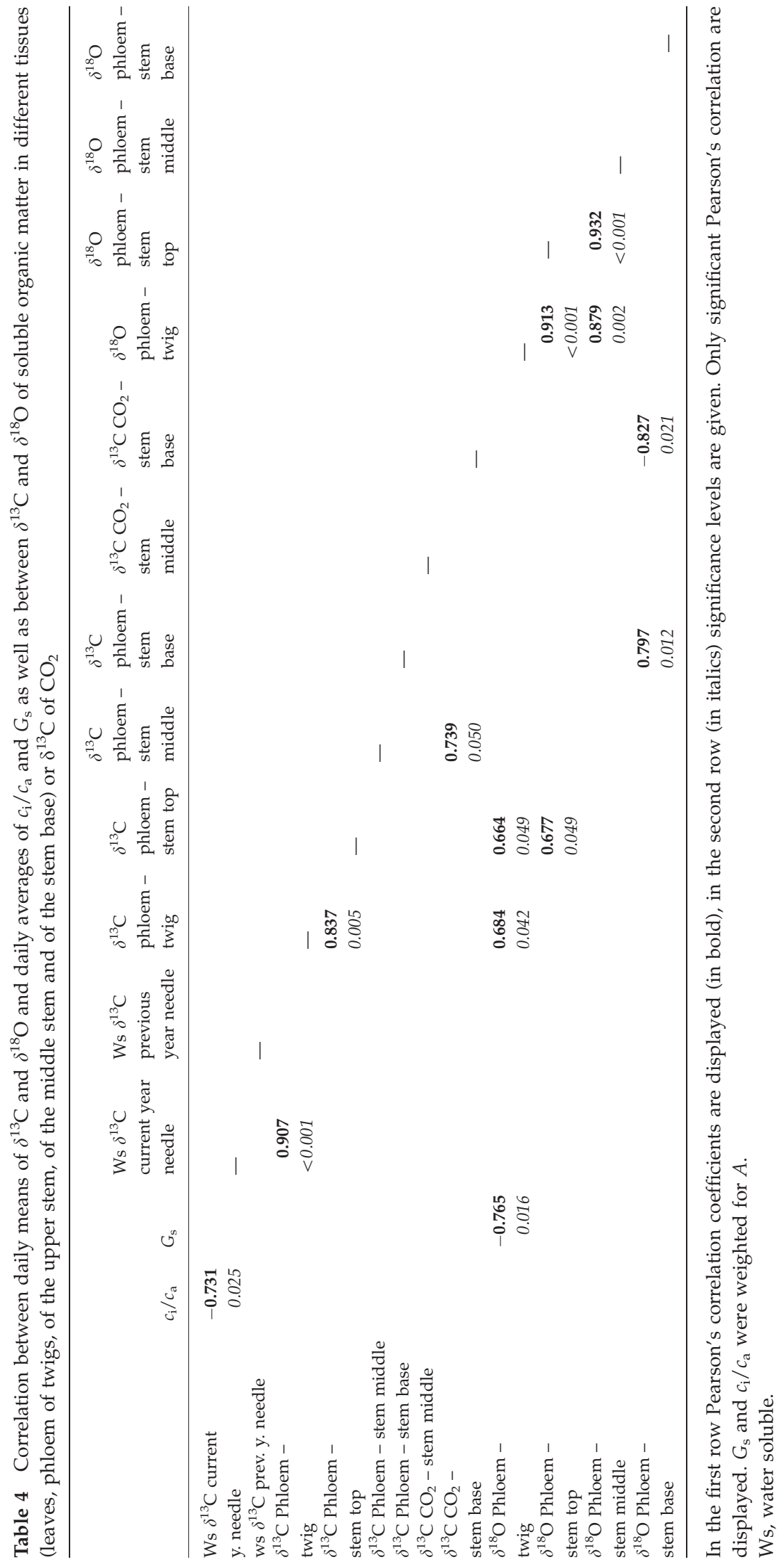


Our findings suggest fractionation steps are active in both leaves (autotrophic tissue) as well as in heterotrophic (or carbon sink) plant tissues. Assuming $\delta^{13} \mathrm{C}$ for source $\mathrm{CO}_{2}$ to be constantly $7.9 \%$, the difference between primary assimilates and the soluble sugar pool support the hypothesis put forward by Hobbie \& Werner (2004). The strong ${ }^{13} \mathrm{C}$ enrichment between the pool of soluble carbohydrates in foliage and sugars transported in twig phloem, points to loading of mainly enriched compounds into the phloem. During transport to heterotrophic plant parts, there is additional enrichment between twigs and stem base. A possible explanation of ${ }^{13} \mathrm{C}$ enrichment during basipetal allocation is provided by the dynamic Münch mass flow model recently reviewed by Van Bel (2003). The model proposes that while a proportion of the sucrose from sieve tubes is released during phloem transport, some two thirds of this is transported back into the sieve tubes (Minchin \& Thorpe, 1987). This process could readily account for increases in $\delta^{13} \mathrm{C}$ of retrieved carbon, depending on the metabolic processes and connected isotopic fractionation the released sucrose is subjected to Gessler et al. (2004). Allocation of released sugar to isotopically lighter lignin would help explain continuous ${ }^{13} \mathrm{C}$ enrichment of sugars along the stem transport path. Postulating of strong exchange between phloem and surrounding tissues in stems is consistent with other evidence suggesting stems comprise mixtures of carbon with different metabolic history and by diel variations in $\delta^{13} \mathrm{C}$ in twig phloem yet strongly damped diel variations in stems.

There was no clear trend throughout the transport pathway in ${ }^{18} \mathrm{O}$ enrichment. Organic matter in twig phloem did not differ in ${ }^{18} \mathrm{O}$ signatures from that in stem bases, yet compounds transported in the middle and upper part of the stem were ${ }^{18} \mathrm{O}$ enriched. This is in contrast to the findings of Cernusak et al. (2005) who saw no basipetal $\delta^{18} \mathrm{O}$ gradients in phloem organic matter.

\section{${ }^{13} \mathrm{C}$ enrichment of $\mathrm{CO}_{2}$ in comparison with carbon sources suggests fragmentation fractionation}

Fractionation processes during respiration may also contribute to interorgan differences of $\delta^{13} \mathrm{C}$ but we lack a clear picture of respiratory carbon fractionation. For example, Lin \& Ehleringer (1997) found no isotopic fractionation during dark respiration; Ghashghaie et al. (2001) and Xu et al. (2004) observed ${ }^{13} \mathrm{C}$ enrichment in leaf respired $\mathrm{CO}_{2}$ compared with its source substrates. Tcherkez et al. (2003, 2004) concluded that nonrandom distribution of ${ }^{13} \mathrm{C}$ in hexose phosphate substrates and fragmentation fractionation during respiration was responsible for this observation. Badeck et al. (2005) observed ${ }^{13} \mathrm{C}$ enrichment of $\mathrm{CO}_{2}$ released from leaves of Phaseolus vulgaris but no change or even depletion of stems and root tissues.

In contrast, $\mathrm{CO}_{2}$ emitted from the stem of Fagus sylvatica (Damesin \& Lelarge, 2003) and of P. sylvestris (Fig. 7) was enriched compared with organic matter. There is no indication in the present study that $\mathrm{CO}_{2}$ emitted from different stem positions differed in carbon isotope signature. However, we cannot exclude that $\mathrm{CO}_{2}$ emitted from twigs or leaves - where $\delta^{13} \mathrm{C}$ of soluble carbon is significantly different compared with the middle stem or stem base - has a different carbon isotope signature.

Day-to-day variation of $\delta^{13} \mathrm{C}$ and $\delta^{18} \mathrm{O}$ are strongly influenced by $\mathrm{c}_{i} / \mathrm{c}_{a}$ and $\mathrm{G}_{s}$, respectively

During the study period, meteorological conditions were rather variable. This induced considerable variation in stomatal conductance, net assimilation rate (in a comparable range as observed for $P$. sylvestris at different sites in Europe; Luoma, 1997) and - to a somewhat lesser extent $-c_{\mathrm{i}} / c_{\mathrm{a}}$. It is generally assumed that the $\delta^{13} \mathrm{C}$ and $\delta^{18} \mathrm{O}$ of water-soluble carbon in leaves or phloem are strongly dependent on $c_{\mathrm{i}} / c_{\mathrm{a}}$ (or on proxies for this value) and on $G_{\mathrm{s}}$, respectively (Brugnoli et al., 1988; Barbour \& Farquhar, 2000; Barbour et al., 2000b; Cernusak et al., 2003; Keitel et al., 2003; Scartazza et al., 2004).

When - in order to smooth the diel variations - daily mean values were calculated for the isotopic composition and the putatively influencing parameters, the correlations between $c_{\mathrm{i}} / c_{\mathrm{a}}$ and $\delta^{13} \mathrm{C}$ in the foliar watersoluble fraction (Table 4; Fig. S3) and between $G_{\mathrm{S}}$ and $\delta^{18} \mathrm{O}$ in the twig phloem (Table 4), lend support to this hypothesis. In contrast to beech (Keitel et al., 2003; Gessler et al., 2004) $G_{\mathrm{s}}$ could not be used as proxy for $c_{\mathrm{i}} / c_{\mathrm{a}}$.

There was additionally no dependence between $\delta^{13} \mathrm{C}$ and net photosynthesis as the second potential factor influencing $c_{\mathrm{i}}$ (Table S1). Instead, a multiple regression model $c_{i} / c_{a}=0.68-7.0210^{-3} A+0.68 G_{s}-0.13 A G_{s}$ including both $G_{\mathrm{S}}$ and $A$ as determinants, explained $59 \%$ of the variation of $c_{\mathrm{i}} / c_{\mathrm{a}}$. This result indicates concerted influence of diffusion and carboxylation on internal $\mathrm{CO}_{2}$ concentration and subsequently photosynthetic carbon isotope discrimination and, thus, should also be reflected by the relation between $\delta^{18} \mathrm{O}$ and $\delta^{13} \mathrm{C}$. The $\delta^{18} \mathrm{O}$ signatures of recently synthesized organic matter share dependence on stomatal conductance with $\delta^{13} \mathrm{C}$ signatures but are not dependent on Rubisco activity (Barbour et al., 2004). The large variation in $\delta^{18} \mathrm{O}$ of phloem organic matter accompanied by much smaller changes in $\delta^{13} \mathrm{C}$, resulting in slopes of the 
regression between the two parameters being much closer to 0 than to 1 (Fig. S4), supports the assumption of a combined influence of $G_{\mathrm{s}}$ and $\mathrm{A}$ on $\delta^{13} \mathrm{C}$ (Scheidegger et al., 2000).

Transport of newly fixed carbon from the leaves to the stem base is likely to take approximately 1 day

The day-to-day variation of twig phloem $\delta^{13} \mathrm{C}$ was mainly influenced by the soluble carbon of current but not of the previous year's needles. This indicates that in the middle of the growing season a major proportion of the carbon exported to the heterotrophic tissues is supplied from the current year foliage. It is obvious that the correlation between foliar and phloem $\delta^{13} \mathrm{C}$ becomes weaker with increasing distance of the phloem sampling position from the canopy. The same pattern could be observed with increasing distance when $\delta^{13} \mathrm{C}$ or $\delta^{18} \mathrm{O}$ of phloem organic matter were correlated. Cross-correlation analysis revealed that correlation coefficients between isotope signatures from canopy and stem base tissues increased when a time lag of 1 day was taken into account. Thus, we conclude that it takes approximately 1 day for the newly fixed carbon to be transported from the leaves to the stem base. Figure $4 \mathrm{~A}$ additionally illustrates this hypothesis: After the second intensive rainfall event $\delta^{13} \mathrm{C}$ drops first in the twig phloem, later on in the upper part of the stem and with a lag of approximately $24 \mathrm{~h}$ (relative to the twig phloem) in the phloem of the stem base. These findings well agree with the observation made by Keitel et al. (2003) and Gessler et al. (2004) of a time lag of 2 days between carbon fixation and transport of this carbon to the stem base of beech. As the beech trees in their study were ca. $25-27 \mathrm{~m}$ high, whereas the pine trees in this study reached $14-15 \mathrm{~m}$, carbon transport velocity was similar in both species (ca. $0.5 \mathrm{~m} \mathrm{~h}^{-1}$ ). Already Zimmermann \& Braun (1971) suggested phloem transport rates for different species of between 0.5 and $1.0 \mathrm{~m} \mathrm{~h}^{-1}$.

\section{Conclusions}

With the data presented we could verify our working hypothesis (1) showing that $\delta^{13} \mathrm{C}$ of newly produced organic matter is strongly influenced by $c_{\mathrm{i}} / c_{\mathrm{a}}$ and that this carbon is allocated in basipetal direction with a transport velocity of approximately $0.5 \mathrm{~m} \mathrm{~h}^{-1}$. There is only one restriction in accepting hypothesis (1) completely: $\delta^{13} \mathrm{C}$ of $\mathrm{CO}_{2}$ was not strongly related to $\delta^{13} \mathrm{C}$ of phloem organic matter as the potential source of respiration. As there was much more variation in $\delta^{13} \mathrm{C}$ of $\mathrm{CO}_{2}$ as compared with phloem organic matter, it might be concluded that strong diel fluctuations in the signature of $\mathrm{CO}_{2}$ released, as observed by Hymus et al. (2005) for leaves, and that we were not able to resolve with our measurements, might have prevented a closer relation.

We also accept our working hypothesis (2) as we found both diel variations that are likely to be due to starch storage and remobilization, and carbon isotope fractionation associated with transport from leaves to the stem. In the latter case fractionation processes in sink and source tissues seem to contribute to the observed effects.

When using carbon isotope signature for partitioning $\mathrm{CO}_{2}$ fluxes on the ecosystem level or for assessing environmental effects like water availability on $c_{\mathrm{i}} / c_{\mathrm{a}}$, it must be considered that photosynthetic carbon isotope fractionation is superimposed by postphotosynthetic discrimination.

\section{Acknowledgements}

The study was financially supported by the state of BadenWürttemberg (Landesforschungsschwerpunkt-Programm) and by the European Union (INTERREG III A, Project 3c.10). A.G. acknowledges personal financial support by a research fellowship from the Deutsche Forschungsgemeinschaft (GE 1090/4-1). The meteorological data were provided from $\mathrm{H}$. Mayer and L. Jaeger (Meteorological Institute of the University Freiburg).

\section{References}

Adams MA, Grierson PF (2001) Stable isotopes at natural abundance in terrestrial plant ecology and ecophysiology: an update. Plant Biology, 3, 299-310.

Badeck FW, Tcherkez G, Nogues S et al. (2005) Post-photo synthetic fractionation of stable carbon isotopes between plant organs - a widespread phenomenon. Rapid Communications in Mass Spectrometry, 19, 1381-1391.

Barbour MM, Andrews TJ, Farquhar GD (2001) Correlations between oxygen isotope ratios of wood constituents of Quercus and Pinus samples from around the world. Australian Journal of Plant Physiology, 28, 335-348.

Barbour MM, Farquhar GD (2000) Relative humidity- and ABAinduced variation in carbon and oxygen isotope ratios of cotton leaves. Plant Cell and Environment, 23, 473-485.

Barbour MM, Fischer RA, Sayre KD et al. (2000a) Oxygen isotope ratio of leaf and grain material correlates with stomatal conductance and grain yield in irrigated wheat. Australian Journal of Plant Physiology, 27, 625-637.

Barbour MM, Roden JS, Farquhar GD et al. (2004) Expressing leaf water and cellulose oxygen isotope ratios as enrichment above source water reveals evidence of a Peclet effect. Oecologia, 138, 426-435.

Barbour MM, Schurr U, Henry BK et al. (2000b) Variation in the oxygen isotope ratio of phloem sap sucrose from castor bean. Evidence in support of the Peclet effect. Plant Physiology, 123, 671-679.

Beck E, Ziegler P (1989) Biosynthesis and degradation of starch in higher plants. Annual Review of Plant Physiology and Plant Molecular Biology, 40, 95-117. 
Brugnoli E, Hubick KT, vonCaemmerer S et al. (1988) Correlation between the carbon isotope discrimination in leaf starch and sugars of C-3 plants and the ratio of intercellular and atmospheric partial pressures of carbon-dioxide. Plant Physiology, 88, 1418-1424.

Cernusak LA, Arthur DJ, Pate JS et al. (2003) Water relations link carbon and oxygen isotope discrimination to phloem sap sugar concentration in Eucalyptus globulus. Plant Physiology, 131, 1544-1554

Cernusak LA, Farquhar GD, Pate JS (2005) Environmental and physiological controls over oxygen and carbon isotope composition of Tasmanian blue gum, Eucalyptus globulus. Tree Physiology, 25, 129-146.

Cernusak LA, Pate JS, Farquhar GD (2004) Oxygen and carbon isotope composition of parasitic plants and their hosts in southwestern Australia. Oecologia, 139, 199-213.

Damesin C, Lelarge C (2003) Carbon isotope composition of current-year shoots from Fagus sylvatica in relation to growth, respiration and use of reserves. Plant Cell and Environment, 26, 207-219.

Farquhar GD, O'Leary MH, Berry JA (1982) On the relationship between carbon isotope discrimination and the inter-cellular carbon-dioxide concentration in leaves. Australian Journal of Plant Physiology, 9, 121-137.

Gessler A, Rennenberg H, Keitel C (2004) Stable isotope composition of organic compounds transported in the phloem of European beech - evaluation of different methods of phloem sap collection and assessment of gradients in carbon isotope composition during leaf-to-stem transport. Plant Biology, 6, 721-729.

Ghashghaie J, Duranceau M, Badeck FW et al. (2001) $\delta^{13} \mathrm{C}$ of $\mathrm{CO}_{2}$ respired in the dark in relation to $\delta^{13} \mathrm{C}$ of leaf metabolites: comparison between Nicotiana sylvestris and Helianthus annuus under drought. Plant Cell and Environment, 24, 505-515.

Gleixner G, Schmidt HL (1997) Carbon isotope effects on the fructose-1,6-bisphosphate aldolase reaction, origin for nonstatistical C-13 distributions in carbohydrates. Journal of Biological Chemistry, 272, 5382-5387.

Gleixner G, Scrimgeour C, Schmidt HL et al. (1998) Stable isotope distribution in the major metabolites of source and sink organs of Solanum tuberosum L.: a powerful tool in the study of metabolic partitioning in intact plants. Planta, 207, 241-245.

Granier A (1985) A New method of sap flow measurement in tree stems. Annales des Sciences Forestieres, 42, 193-200.

Granier A, Biron P, Breda N et al. (1996) Transpiration of trees and forest stands: Short and long term monitoring using sap flow methods. Global Change Biology, 2, 265-274.

Haberer K (2002) Auswirkungen von apoplastischem Ascorbat sowie weiteren physiologischen und meteorologischen Parametern auf den $\mathrm{NO}_{2}$-Gaswechsel von Pflanzen. PhD thesis, Geowissenschaftliche Fakultät der Albert-Ludwigs-Universität Freiburg.

Helle G, Schleser GH (2004) Beyond $\mathrm{CO}_{2}$-fixation by Rubisco an interpretation of $\mathrm{C}-13 / \mathrm{C}-12$ variations in tree rings from novel intra-seasonal studies on broad-leaf trees. Plant Cell and Environment, 27, 367-380.

Hobbie EA, Werner RA (2004) Intramolecular, compound-specific, and bulk carbon isotope patterns in C-3 and C-4 plants: a review and synthesis. New Phytologist, 161, 371-385.
Hymus GJ, Maseyk K, Valentini R et al. (2005) Large daily variation in C-13-enrichment of leaf-respired $\mathrm{CO}_{2}$ in two Quercus forest canopies. New Phytologist, 167, 377-384.

Jaggi M, Saurer M, Fuhrer J et al. (2002) The relationship between the stable carbon isotope composition of needle bulk material, starch, and tree rings in Picea abies. Oecologia, 131, 325-332.

Keeling CD (1958) The concentration and isotopic abundances of atmospheric carbon dioxide in rural areas. Geochimica et Cosmochimica Acta, 13, 322-334.

Keitel C, Adams MA, Holst T et al. (2003) Carbon and oxygen isotope composition of organic compounds in the phloem sap provides a short-term measure for stomatal conductance of European beech (Fagus sylvatica L.). Plant Cell and Environment, 26, 1157-1168.

Kendall SM, Ord JK (1990) Time Series, 3rd edn. Oxford University Press, New York.

Kostner B, Biron P, Siegwolf R et al. (1996) Estimates of water vapor flux and canopy conductance of Scots pine at the tree level utilizing different xylem sap flow methods. Theoretical and Applied Climatology, 53, 105-113.

Kostner B, Granier A, Cermak J (1998) Sapflow measurements in forest stands: methods and uncertainties. Annales des Sciences Forestieres, 55, 13-27.

Lin GH, Ehleringer JR (1997) Carbon isotopic fractionation does not occur during dark respiration in C-3 and C-4. Plant Physiology, 114, 391-394.

Luoma S (1997) Geographical pattern in photosynthetic light response of Pinus sylvestris in Europe. Functional Ecology, 11, 273-281.

Mayer H, Gietl G (1976) Bioklimatische Unterschiede zwischen einer Stadt- und einer Waldatmosphäre. International Journal of Biometeorology (Historical Archive), 20, 325-332.

Mayer H, Jaeger L, Matzarakis A et al. (2000) Forstmeteorologische messstelle hartheim des meteorologischen instituts der Universität Freiburg. Berichte des Meteorologischen Instituts der Universität Freiburg, 5, 55-83.

Minchin PEH, Thorpe MR (1987) Measurement of unloading and reloading of photo-assimilate within the stem of bean. Journal of Experimental Botany, 38, 211-220.

Newton HJ (1996) Timeslab: A Time Series Analysis Laboratory. Wadsworth \& Brooks/Cole, Pacific Grove.

Nogues S, Tcherkez G, Cornic G et al. (2004) Respiratory carbon metabolism following illumination in intact french bean leaves using ${ }^{13} \mathrm{C} /{ }^{12} \mathrm{C}$ isotope labeling. Plant Physiology, 136, 32453254.

Pataki DE, Ehleringer JR, Flanagan LB et al. (2003) The application and interpretation of Keeling plots in terrestrial carbon cycle research. Global Biogeochemical Cycles, 17, 1022.

Pataki DE, Oren R, Phillips N (1998) Responses of sap flux and stomatal conductance of Pinus taeda L. trees to stepwise reductions in leaf area. Journal of Experimental Botany, 49, 871878.

Rennenberg H, Schneider S, Weber P (1996) Analysis of uptake and allocation of nitrogen and sulphur compounds by trees in the field. Journal of Experimental Botany, 47, 1491-1498.

Sachs L (1984) Angewandte Statistik. Springer, 6. Auflage. Berlin.

Scartazza A, Mata C, Matteucci G et al. (2004) Comparisons of $\delta^{13} \mathrm{C}$ of photosynthetic products and ecosystem respiratory 
$\mathrm{CO}_{2}$ and their response to seasonal climate variability. Oecologia, 140, 340-351.

Scheidegger Y, Saurer M, Bahn M et al. (2000) Linking stable oxygen and carbon isotopes with stomatal conductance and photosynthetic capacity: a conceptual model. Oecologia, 125, 350-357.

Schmidt HL (2003) Fundamentals and systematics of the nonstatistical distributions of isotopes in natural compounds. Naturwissenschaften, 90, 537-552.

Schneider S, Gessler A, Weber P et al. (1996) Soluble N compounds in trees exposed to high loads of $\mathrm{N}$ : a comparison of spruce (Picea abies) and beech (Fagus sylvatica) grown under field conditions. New Phytologist, 134, 103-114.

Tcherkez G, Farquhar GD (2005) Carbon isotope effect predictions for enzymes involved in the primary carbon metabolism of plant leaves. Functional Plant Biology, 32, 277-291.

Tcherkez G, Farquhar G, Badeck F et al. (2004) Theoretical considerations about carbon isotope distribution in glucose of C-3 plants. Functional Plant Biology, 31, 857-877.

Tcherkez G, Nogues S, Bleton J et al. (2003) Metabolic origin of carbon isotope composition of leaf dark-respired $\mathrm{CO}_{2}$ in French bean. Plant Physiology, 131, 237-244.

Terwilliger VJ, Kitajima K, Le Roux-Swarthout DJ et al. (2001) Influences of heterotrophic and autotrophic resource use on carbon and hydrogen isotopic compositions of tropical tree leaves. Isotopes in Environmental and Health Studies, 37, 133-160.

Van Bel AJE (2003) The phloem, a miracle of ingenuity. Plant Cell and Environment, 26, 125-149.

von Caemmerer S, Farquhar GD (1981) Some relationships between the biochemistry of photosynthesis and the gas exchange of leaves. Planta, 153, 376-387.

Whitehead D, Jarvis PG (1981) Coniferous forests and plantations. In: Water Deficits and Plant Growth, Vol. VI (ed. Kozlowski TT), pp. 49-52. Academic Press, San Diego.

$\mathrm{Xu}$ CY, Lin GH, Griffin KL et al. (2004) Leaf respiratory $\mathrm{CO}_{2}$ is $\mathrm{C}$-13-enriched relative to leaf organic components in five species of C-3 plants. New Phytologist, 163, 499-505.

Zimmermann MH, Braun CL (1971) Trees, Structure and Function. Springer, Berlin.

\section{Supplementary Material}

The authors have provided the following supplementary material, which is available alongside the article at http:/ / www.blackwell-synergy.com:

Table S1: Correlation between daily means of $\delta^{13} \mathrm{C}$ and $\delta^{18} \mathrm{O}$ and daily average of $c_{\mathrm{i}} / c_{\mathrm{a}}, G_{\mathrm{s}}, \mathrm{A}$, and meteorological parameters. In the first row Pearson's correlation coefficients are displayed in the second row (in italics) significance levels are given. Bold figures indicate Pearson's correlation to be significant. $G_{\mathrm{s}}$ and $c_{\mathrm{i}} / c_{\mathrm{a}}$ were weighted for $A$.

Table S2: Correlation between daily averages of $\delta^{13} \mathrm{C}$ and $\delta^{18} \mathrm{O}$ of soluble organic matter in different tissues (leaves, phloem of twigs, of the upper stem, of the middle stem and of the stem base) or $\delta^{13} \mathrm{C}$ of $\mathrm{CO}_{2}$. In the first row Pearson's correlation coefficients are displayed in the second row (in italics) significance levels are given. Bold figures indicate Pearson's correlation to be significant

Fig. S1: Canopy stomatal conductance $\left(G_{\mathrm{s}}\right)$ plotted against leaf level stomatal conductance $\left(g_{\mathrm{s}}\right)$. The regression line displayed was forced through zero. $G_{\mathrm{s}}$ was calculated as half hourly mean value from sap flow densities measured with 12 trees according to Eqn (1); $G_{\mathrm{s}}$ was determined for 4 trees 4 times a day using a portable photosynthesis measurement device (LC A4) and correlated with $G_{\mathrm{s}}$ determined at the same times. Data were omitted when RH values close to $100 \%$ occurred which may have lead to an overestimation of the canopy level $G_{\mathrm{s}}$ calculations (see discussion)

Fig. S2: 9-day-average starch concentrations in current year needles. Needle samples were collected four times each day: in the morning (between 8:00 and 10:00), at midday/afternoon (12:45-15:00), in the evening (17:30-20:00) and during night (22:00-01:00). Data shown are mean values from one tree $\pm \mathrm{SE}$.

Fig. S3: Regression line (black line) between daily means of $c_{\mathrm{i}} / c_{\mathrm{a}}$ and $\delta^{13} \mathrm{C}$ of the water soluble organic matter of current year needles. $c_{\mathrm{i}} / c_{\mathrm{a}}$ was weighted for $A$. The bold blue line is $\delta^{13} \mathrm{C}$ calculated from Eqn (2) assuming $\delta^{13} \mathrm{C}$ of atmospheric $\mathrm{CO}_{2}$ amounting to constantly $-7.9 \%$.

Fig. S4: Regression lines between $\delta^{18} \mathrm{O}$ and $\delta^{13} \mathrm{C}$ of phloem organic matter from the twig phloem and the phloem from the upper and lower stem (base). Data shown are daily mean values from 4 trees measured at 4 time points per $24 \mathrm{~h}$. 